\title{
Development and Validation of an Adult Greek-American Identity Scale
}

\author{
Stavros T. \\ Constantinou \\ The Ohio State University
}

\author{
Milton E. \\ Harvey \\ Kent State University
}

\author{
Karen H. \\ Larwin \\ Youngstown State University
}

The current investigation demonstrates the development of an identity instrument, specifically for the measurement of Greek-American ethnic identity: the Adult GreekAmerican Identity Scale (AGIS). This scale construct validity was assessed with data collected from six Greek Orthodox parishes in northeastern Ohio. As an expansion of earlier research, this study demonstrates that the Greek-American Identity Scale successfully captures the salient elements of this complex and multifaceted phenomenon under four constructs: Ethos, Network, Diaspora, and Attitude. This study makes contributions to three areas of ethnic studies. First, it contributes to the literature on Greek-Americans, a small and understudied ethnic group. Second, this study provides an example of scale development which, although ethnic group specific, can be modified and applied to other ethnic groups. Third, this study makes a contribution to the growing literature that uses structural equation modeling (SEM) in the study of ethnic identity.

Keywords: ethnic identity, Adult Greek-American Identity Scale (AGIS), structural equation modeling (SEM), construct, second-order model

Greek ethnicity is an understudied phenomenon. As it is with Jews and Armenians, Greek diaspora is substantial (Clogg, 1999, p. 1). Greek diaspora consists of communities in the United States, Canada, Australia, South Africa, South America, and Europe. Greek-Americans, one of the smaller ancestry groups in the United States, represent only $0.4 \%$ of the total U.S. population (USCB, 2016). As a result, Greek-Americans are one of the overlooked and understudied ethnic groups (Issari, 2011). The emergence and perpetuation of a Greek diaspora imply that Greeks, and, specifically, Greek-Americans, have contact with diverse dominant cultural groups and have likely of adopted aspects of these other cultures.

The systematic analyses of this interaction between immigrant and dominant culture have coalesced into a field of study identified as acculturation. Redfield, Linton, and Herskovits (1936) proposed this preferred definition of acculturation: "Acculturation comprehends those phenomena which result when groups of individuals having different cultures come into continuous first-hand contact, with subsequent changes in the original culture patterns of either or both groups" (p. 149). Acculturation is voluntary and represents the degree to which an individual elects to participate in the cultural traditions, values, beliefs, 
and practices of the dominant culture (Rudmin, 2003; Schwartz \& Zamboanga, 2008; Schwartz, Unger, Zamboanga, \& Szapocznik, 2010).

Acculturation is a sub-process of ethnic change, and many investigations on Greek ethnicity are acculturation studies (Laroche, Kim, \& Hui, 1997). A sub-concept of acculturation is ethnic identity, which is the degree to which a person holds on to some of the traditions of their ethnic group while adopting markers from the dominant culture (Schinkel, 2013). It is the subjective feelings about one's identity-individuals' views of themselves as part of a group, a sense of belonging and loyalty, and therefore a vested interest in the survival of the group (Phinney 1992, Rotheram \& Phinney, 1988). Constantinou and Harvey (1985) empirically tested a two-dimensional model of Greek identity that consists of internalities and externalities. The former consists of items that bind individual ethnics as a community within the host society, whereas, the latter emphasizes the role of emotional linkages and orientation of GreekAmericans to the ancestral homeland. Later, Constantinou (1989) identified three dominant themes of Greek-American ethnicity: lingua, which reflects the importance of language as an integral part of Hellenic identity; cultura, which comprises sociocultural activities sponsored by the parish church and affiliated organizations; and politika, which underscores the role of politics as a major aspect of Greek-American ethnicity. The purpose of the present study is to develop and test a theoretically derived and psychometrically validated scale, the AGIS, which captures the comprehensive measure of ethnic identity for adult Greek-Americans.

Sibley and Houkamau (2013) maintain that there is a need for "culturespecific measures of identity" (p.97) which can fill the void currently existing in the extant literature. They posit that that the development of culture-specific measures can highlight nuances of identity such as language, food, interpretations, that are exclusive to each cultural group. The ability to accurately measure ethnic identity is important to the wider research community. For instance, researchers in the social sciences have found that ethnic identity is associated with individual psycho-social wellbeing (Ikran, Snijder, Wit, Schene, Stronks, \& Kunst, 2016; Umana-Taylor, Diversi, \& Fine, 2002), as well as issues of discrimination and coping (Phinney \& Chavira, 1995; Fuller-Rowell, Ong, \& Phinney, 2012). Likewise, researchers have found that aspects of ethnic identity can be predictive of different ethnic groups economic stability and mobility (Casey \& Dustmann, 2010; Constant \& Zimmerman, 2008). The development of valid and reliable measures of ethnic identity is necessary for consistency of measurement in ethnic identity related research (Phinney \& Ong, 2007).

The most recent Greek-specific scales of relevance to Greek identity study include the investigation by Vlachopoulos, Moustaka, and Anderson 
(2008). They translated the Exercise Identity Scale proposed by Anderson and Cychosz (1994) and Anderson, Cychosz, and Franke (2001) into Greek and examined its psychometric properties. A similar work is the study of the role of dance as an important part of Greek-American ethnic identity by Issari (2011). Similar to these studies, the AGIS is ethnic-group specific. However, the AGIS is unique in that it seeks to measure ethnic identity more broadly than these earlier inventories, expanding on Constantinou's and Harvey's (1985) two-dimensional model.

\section{AGIS Four Factor Model}

The AGIS model measures three internal factors and one external factor. The internal component converges on the subscales of ethos, network, diaspora, and the external component converges on the subscale of attitude. First, ethos refers to how an individual or a group chooses to live. It refers to the fundamentals of a particular culture and the underlying belief system that influences the character of a person or group. Based on his work among ethnic groups in the Copper Belt of Zambia, Epstein (2006) defined ethos as "the identifiable thread of continuity of a group...the structure of assumptions, values, and meanings which underlie particular and varying expressions of cultural behavior" (p. 122). According to Epstein, this shared identity may be a specific sense of belonging that is time specific.

Among the tribes of the Copper Belt, the factors that foster this sense of collective identity include the sharing of a language, a religion, and traditions. The customs identified by Epstein (2006) may also be manifested in community activities that occur in particular places and at particular times. In this context, Chacko (2003) described the ethos of the Ethiopian immigrants in the Washington, D.C., metropolitan area in this manner:

their cultural characteristics and values as a people, found expression in the formation of ethnic places, or locales with a distinctively ethnic stamp. . . (they are the) different places where ethnic affiliation lays the foundation on which a sense of unity is created. (p. 22)

Additionally, she examined the roles of these places in maintaining the community by catering to its diverse needs.

For ethnic Greek-Americans, the spatial manifestations of ethos include the parish church and other places where the community gathers for lectures, dances, and other ethnic-related activities, such as picnics. Chacko's (2003) description of the setting in some Ethiopian stores in the Washington, D.C., metropolitan area is equally appropriate to many Greek ethnic stores in any large metropolitan area in the United States and Canada: "Some stores offer a few chairs grouped around a table for clients who wish to sit down and socialize over a cup of coffee or a snack" (p. 33). Functionally, such stores may also sell ethnic language newspapers and 
provide information on community-related activities. In addition, they are venues for discussions of politics and sports. In the implementation of aspects of ethos, Greek-American communities create and interact in networks that operate within the Greek-American diaspora. Furthermore, ethos influences attitudes about Greek identity and those aspects of Greek culture that affect how Greek culture evolves in the United States.

Secondly, the AGIS measures networks which result because people with certain attributes (religion, race, or ethnicity) choose to associate with each other. The importance of social networking for immigrant communities and their families is pivotal to navigating a plethora of issues. These include employment, discrimination, and feelings of belonging (Ikran, et al., 2016). Aldrich and Waldinger (1990) conceptualized the social structure of ethnic groups as "networks of kinship and friendship around which ethnic communities are arranged, and the interlacing of these networks with positions in the economy (jobs), in space (housing), and in society (institutions)" (p. 127). The need for ethnic groups to work together is central to conservation of a cultural norms, traditions, and nuances.

As Breton (1964, p.194) observed, "ethnic communities can vary enormously in their social organization." At one extreme, the existence of a community consists essentially of a network of interpersonal relations; members of a certain ethnic group seek each other's companionship and form friendship groups and cliques. In a different context, a social network that is functionally similar to ethnic network is with the social network provides a great resource of information sharing within their groups, which may help to "decrease externalities by building trust and encouraging reciprocity within their community" (Barnes-Mauthe, Arita, Allen, Gray, \& Leung, 2013, p. 9). For an individual Greek-American, like members of other ethnic groups, these networks operate across the ecological systems' levels, with Greek language being central to a microlevel in the family and the neighborhood, the meso-level of the local community, and the macro-level of the global ethnic community (Bronfenbrenner, 1999).

Next, the AGIS captures a measure of diaspora, described as the dispersion of something that was originally localized, such as a people, language, or culture. As Larkin (2006) elucidated "diaspora refers not simply to dispersal but to the strategies the dispersed peoples employed to retain and/or reproduce their cultural heritage in the context of their new situation as a minority population in a host nation" (p. 167). Although originally associated with the forced exodus of the Jews from Babylon (576 $\mathrm{BC}$ ), the word is now applied to the dispersal of other ethnic groups such as the Greek diaspora (Clogg, 1999) and the Ethiopian diaspora (Deffa, 2016). Because of the increase in the number of ethnic diasporic communities, scholars revised and extended the meaning of the term 
diaspora. As Voutira (2006, p. 381) pointed out, "during the 1990 , the term attracted the attention of anthropologists, sociologists, geographers, political scientists, and cultural critics searching for more comprehensive analytical terms to accommodate the admittedly complex transnational and global linkages among economies, cultures, and peoples."

At any point in time, the culture of the diasporic community is a blend of motherland and host-land attitudes, beliefs, and behavior (Mokrushyna, 2013). These dynamics affect the attitudes and behaviors of individuals in the diaspora toward global events that threaten the survival of parts, or the entire homeland. Other overt activities that accentuate the ties of ethnic Greeks to the homeland include ownership and display of the Greek flag, as well as observance of Greek national holidays, Greek ethnic schools, and the Greek language in the diaspora. The debate on the continuance of the liturgy in Greek reflects the growing influence of the dominant languages and cultures in different parts of the diaspora. Across the generations, these cultural and linguistic influences are expected to decrease (Moskos \& Moskos, 2014).

Lastly, the AGIS measures one external factor of attitude. This concept of attitude for the current investigation refers to an individual's attitude regarding ethnic identity as well as the individual's attitude regarding other ethnic groups. The attitudes of Greek-Americans, as Danopoulos (2005) noted, can be described as an "interaction between two nationstates and their cultural and political markets, and their attempts to remain faithful to the motherland while maximizing their group interests in the United States, that the immigrants construct a new set of group attitudes (p.9).” The longer Greek-Americans, or any ethnic group, reside in the United States, the more particular cultural attitudes are modified in the family, the Church, and regarding the importance of the Greek language. Attitudes toward one's own ethnic group, as well as other groups, are one of the four components of ethnic identity (Phinney, 1996). Valk and Karu (2001) defined ethnic identity as (a) a combination of attitudes toward one's group of origin and its common cultural practices, and (b) one's feeling of attachment to the group. The interrelationship between "ethnic identity and ethnic attitude has been found to be predictive of, for example attitudes toward fighting among the African American and Latino and Latina" (Arbona, Jackson, McCoy, \& Blakely, 1999, p. 326). Orozco (2007) summarized the connections between strong attachment to one's ethnic group and attitudes toward the group. These individuals with high levels of ethnic identity demonstrate their commitment to their ethnic identity by way of engagement in traditional ethnic activities, optimistic identification as a group member, and through positive endorsement of the group to which they identify (p.9).

In contrast, individuals low on ethnic identity are said to have little ethnic interest, endorse negative evaluations of the group and of their 
membership in the group, and lack knowledge of, commitment to, or involvement in their group (p. 9). Therefore, an individual's ethnic attitude consists of an individual's evaluative reaction toward a certain ethnic norm and practice, and the degree to which the individual agrees or disagrees with statements about the importance of that ethnic norm.

\section{Method}

\section{Data}

The data for this study derive from a survey among six Greek Orthodox parishes in the Cleveland Standard Consolidated Statistical Area (Constantinou, 1982). Given that approximately 80\% of Greek-Americans are dues-paying members of the Greek Orthodox Church (Constantinou \& Harvey, 1985; Moskos, 1980), a sample drawn from church records is representative of the Greek community at large. Such a sample of a Greek ethnic community is ideal for studying various aspects of ethnic identity (Boukourakis, 2006; Karapanagiotis, 2008; Laroche, Kim, Tomiuk, Belisle, 2005; Nicolaidis, 1989; Rosenthal \& Hrynevich, 1985).

The mean age of the total sample falls into the 35 to 44 years category; individual ages were collapsed into the following age categories: 20-24, 25-34, 35-44, 45-54, 55-59, 60-64, 65-74, and 75+. More than one-half of the sample $(52.7 \%)$ was male $58.1 \%$ of the respondents had at least one year of post-secondary education, and they earned more than \$50,000 per year. About $71 \%$ of the participants had visited Greece at least once. Given that all the variables are on a five-point Likert scale, the degree of deviation of a mean of 2.5 reflects the extent of participation or nonparticipation in an activity. These data are unique because they provide information on three generations of Greek-Americans in six parishes in northeast Ohio, and they are ideal for testing the seven hypotheses of this study. Recent focus group surveys collected during 2005,2007 , and 2011 in the same geographic area, validate the attributes of the original data collection's participants (Constantinou \& Harvey 2006; Constantinou, 2011).

\section{Precursor Analyses}

Item Development. The sample consisted of 446 completed questionnaires, from which forty-seven Likert-type items were selected that reflect the four factors of Greek-American ethnic identity. This list is all the items in the survey by Constantinou (1982a) that may load on at least one of the four conceptualized dimensions of Greek-American identity. An exploratory factor analysis (EFA), with varimax rotation on the correlation matrix, was constrained to a four-factor solution. The four 
resulting factors (one for each of the constructs), and items with loadings greater than 0.40 were retained for further consideration. This 0.40 filter was used because all the items that were retained loaded on a single factor; 18 for the first, 12 for the second, nine for the third, but only six for the fourth. The pool of items for the fourth factor was increased to nine by the addition of three items with high cross loadings. For the first and second subscales, only the top nine items with the highest loadings were retained. Next, the number of items for each subscale was systematically reduced by limiting the items to those with the highest reliability coefficients, until only four items were kept: Reliability Analysis allows for the study the properties of measurement scales and the items that compose the scales. For example, with nine items the $\alpha$-value for the Ethos subscale is 0.85 but for the four items that are retained to measure this subscale, the $\alpha$-value dropped to 0.74 . This value is larger than the recommended 0.70 threshold for Cronbach's a (George \& Paul, 2014; Nunnaly, 1978).

The resulting Greek-American Identity Scale is a four-factor inventory for measuring the factors of Greek-American identity: (1) ethos, (2) network, (3) diaspora, and (4) attitude. The four items retained to measure the ethos subscale are as follows: the importance of knowledge of Greek language, protest messages to congressmen and senators, correspondence with Greece, and emotional orientation toward Greece. Using a similar process, four items were selected for each of the other three subscales. The network subscale comprises the following variables: frequency of participation in church and other organized activities (parties, picnics, dances, or dinners). The diaspora subscale consists of these variables: close watch of Greek politics, close watch of Cypriot politics, listening to Greek radio at home, and effect of American politics on voting choices. The attitude subscale encompasses the following variables: the emphasis of the Greek language in the liturgy, the importance of Greek in interpersonal communication, the focus of Greek-American youth learning the Greek language, and Greek parochial schools should be organized in every community. Table 1 summarizes the basic statistics for these 16 items. 
Table 1

Basic Statistics for Total Sample, $N=446$

\begin{tabular}{|c|c|c|c|c|}
\hline Item & $M$ & $S D$ & $S k$ & Krt \\
\hline X1: Importance of knowledge of Greek language & $3 \cdot 55$ & 1.22 & -0.54 & -0.59 \\
\hline $\begin{array}{l}\text { X2: Frequency of protesting to congress } \\
\text { representatives }\end{array}$ & 3.15 & 1.51 & -0.11 & -1.41 \\
\hline X3: Frequency of correspondence with Greece & 3.09 & 1.48 & -0.15 & -1.34 \\
\hline $\begin{array}{l}\text { X4: Degree of emotional orientation toward } \\
\text { Greece }\end{array}$ & 3.96 & 1.05 & -0.94 & 0.36 \\
\hline $\begin{array}{l}\mathrm{X}_{5} \text { : Office in church or Greek American } \\
\text { organization }\end{array}$ & 2.58 & 1.34 & 0.23 & -1.14 \\
\hline X6: Discussions about Greece & 3.04 & 1.36 & -0.15 & -1.11 \\
\hline $\begin{array}{l}\text { X7: Participation in church and organized } \\
\text { committees }\end{array}$ & 2.78 & 1.42 & 0.09 & -1.30 \\
\hline X8: Attendance at Greek American conventions & 2.26 & 1.41 & 0.71 & -0.85 \\
\hline X9: Close watch on Greek politics & 2.90 & 1.37 & 0.17 & -1.15 \\
\hline X10: Close watch on Cypriot politics & 2.75 & 1.42 & 0.29 & -1.22 \\
\hline X11: Listens to Greek radio at home & $3 \cdot 33$ & 1.40 & -0.32 & -1.15 \\
\hline X12: Effect of American politics on voting choices & 2.78 & 1.50 & 0.16 & -1.38 \\
\hline X13: Greek should be emphasized in the liturgy & 3.20 & 1.35 & -0.05 & -1.33 \\
\hline $\begin{array}{l}\text { X14: Importance of Greek in interpersonal } \\
\text { communication }\end{array}$ & $3 \cdot 43$ & 1.16 & -0.35 & -0.96 \\
\hline X15: Greek American youth should learn Greek & 4.07 & 0.87 & -1.16 & 1.63 \\
\hline $\begin{array}{l}\text { X16: Greek parochial schools should be in every } \\
\text { community }\end{array}$ & 3.73 & 1.12 & -0.62 & -0.47 \\
\hline
\end{tabular}

Note:As indicated in Table 1., skewness (Sk) and kurtosis (Krt) are within acceptable limits (Tabachnik \& Fidell, 2013).

\section{Data Transformation}

An important underlying assumption of the maximum likelihood estimators employed in covariance-structural analysis methods is that the data are measured on a continuous scale. Although many scholars have treated ordinal data as if they were continuous, Jöreskog (2002-2005, p. 3) strongly cautioned that "ordinal data have no origins or units of measurement and to use ordinal variables in structural equation models requires other techniques than those that are traditionally employed with 
continuous variables." Flora, Finkel, and Foshee (2003) identified some of the consequences of treating ordinal data as continuous data: "biased model fit statistics ... negatively biased parameter estimates, inflated error variances, and extraction of spurious factors." In order to overcome these issues, the ordinal data responses are transformed into continuous data as formulated in threshold theory. The ordinal variable is mapped onto a continuous normal curve by establishing thresholds for each level of the ordinal variable (Table 2). With these thresholds, PRELIS 2.80 is utilized to create the following three matrices that are the input into the measurement models: the asymptotic covariance (ACP), polychoric correlations (PM), and a vector of means (ME).

Table 2

Threshold Transformation of Ordinal Scale Items: Univariate Marginal Parameters, $N=446$

\begin{tabular}{|c|c|c|c|c|}
\hline Items & $M$ & $S D$ & Thre & olds \\
\hline X1: Importance of knowledge of Greek & & & & \\
\hline language & 2.63 & 1.88 & 2.34 & 3.85 \\
\hline $\mathrm{X} 2$ : Frequency of protesting to congress & & & & \\
\hline representatives & 1.72 & 2.10 & 2.09 & 2.89 \\
\hline X3: Frequency of correspondence with Greece & 2.08 & 2.80 & 2.54 & 4.08 \\
\hline X4: Degree of emotional orientation toward & & & & \\
\hline Greece & 3.19 & 1.71 & 2.15 & 3.79 \\
\hline X5: Office in church or Greek American & & & & \\
\hline organization & 1.44 & 3.27 & 3.59 & 5.70 \\
\hline X6: Discussions about Greece & 2.36 & 2.88 & 3.16 & 5.08 \\
\hline X7: Participation in church and organized & & & & \\
\hline committees & 1.62 & 2.95 & 2.83 & 4.72 \\
\hline X8: Attendance at Greek American conventions & 0.28 & 2.76 & 2.50 & 3.66 \\
\hline X9: Close watch on Greek politics & 1.29 & 1.48 & 1.95 & 2.62 \\
\hline X10: Close watch on Cypriot politics & 1.06 & 1.62 & 1.86 & 2.58 \\
\hline X11: Listens to Greek radio at home & 2.16 & 2.08 & 2.22 & 3.39 \\
\hline $\begin{array}{l}\text { X12: Effect of American politics on voting } \\
\text { choices }\end{array}$ & & & & 406 \\
\hline $\begin{array}{l}\text { choices } \\
\text { X13: Greek should be emphasized in the liturgy }\end{array}$ & $\begin{array}{l}1.45 \\
1.27\end{array}$ & $\begin{array}{l}2.95 \\
1.00\end{array}$ & 2.06 & 4.00 \\
\hline X14: Importance of Greek in interpersonal & & & נכ. 1. & \\
\hline communication & 1.53 & 0.89 & 1.37 & 2.34 \\
\hline X15: Greek American youth should learn Greek & 2.95 & 1.33 & 1.63 & 3.60 \\
\hline $\begin{array}{l}\text { X16: Greek parochial schools should be in } \\
\text { every community }\end{array}$ & 2.17 & 1.20 & 1.74 & 2.84 \\
\hline
\end{tabular}

Note. Primary threshold values equal zero; secondary values equal one. 


\section{Psychometric Properties}

Two complementary aspects of construct validity are convergent and discriminant validity. The former is a summary of the degree of agreement between different measurements of a construct, while the latter refers to the degree to which measures of different constructs are unique and assess the difference between constructs.

Convergent validity or reliability. For assessing subscale reliability, the most commonly used measure is Cronbach's $\alpha$, partly because it is easy to interpret and partly because "it is objective and does not require subjective decisions; therefore it is straightforward to use" (Yanyun \& Green, 2011, p. 377). Researchers, however, generally assume that $\alpha$ is the lower bound of scale reliability. Cronbach and Shavelson (2004, p. 204) concurred with this tendency because of a small mathematical detail that causes the alpha coefficient to run "a trifle lower than the desired value." But as Raykov (2001, p.74) reported, " $\alpha$ can also result in a spuriously high reliability in theoretically and empirically relevant cases, namely, congeneric tests with correlated errors." It is incorrect to always consider a lower bound of reliability.

A better alternative is the structural equation-based estimate, the composite reliability (CR) value. As Brown (2006, p. 345) noted, an appealing feature of this approach is that "it provides an estimate of scale reliability directly in the context of the CFA measurement model." The CR is used to calculate the internal consistency of the subscales, specifically, EQS 6.1 for Windows (Build 97) with the RELIABILITY option. The CR ( $\rho$ ) and the corresponding Cronbach's $\alpha$-values for the subscales are as follows: ethos with $\alpha=0.78$ and $\rho=0.79$; network with $\alpha=0.73$ and $\rho=$ 0.74 ; diaspora with $\alpha=0.83$ and $\rho=0.83$; and attitude with $\alpha=0.77$ and $\rho=0.79$.

The fact that both $\alpha$ and $\rho$ are greater than 0.70 indicates that the subscales converge on their hypothesized manifest variables (Anastasiadou, 2014).

Discriminant validity. Commenting on the importance of discriminant validity in analysis involving structural equation modeling (SEM), Farrell (2010, p. 324) wrote that discriminant validity establishment is crucial for conducting the latent variable analysis. . . . Without it, researchers cannot be certain whether results confirming hypothesized structural paths are real or whether they are a result of statistical discrepancies. A nonsignificant discriminant validity measure between a pair of constructs implies that those two constructs are essentially the same." In testing the integrity of subscales, any index of subscale discrimination must be statistically significant. Normal Theory Weighted least squares chi-square $\left(\chi^{2}\right)$ is used in the analysis instead of the Satorra-Bentler scaled chi-square, because some of the models are nested 
(Bryant \& Satorra, 2012). First, the discriminant validity of the concepts is assessed, then confidence bands are constructed around those values.

Discriminant validity is computed with the following nested, chisquare model approach: For any pair of subscales, the freely estimated correlated SEM are fitted (M1) and then a nested model (M2) are fitted with the perfect factor intercorrelation between the two (M2). The difference between the unconstrained and the constrained is chi-squared distributed $\left(\Delta \chi^{2}\right)$, with M2 - M1 degrees of freedom. As Huang and Michael (2000, p. 782) pointed out, "if the $\Delta \chi^{2}$ between the constrained and unconstrained models is statistically significant, it is likely that the correlation for the given pair of factors is indeed not one." This outcome would support an interpretation of discriminant validity between latent factors. Anderson and Gerbing (1988), and Tsigilis, Koustelios, and Togi (2004) made similar observations. Table 3 reports the results for each pair of subscales. They show that the constructs are distinct and measure specific facets of adult Greek ethnic identity.

Table 3

Discriminant Validity of the Four Scales by the Model Difference Method

\begin{tabular}{llrcccc}
\hline $\begin{array}{l}\text { Construct } \\
\text { Pair }\end{array}$ & \multicolumn{1}{c}{ Model } & \multicolumn{1}{c}{$\chi^{2}$} & $d f$ & $\Delta \chi^{2}$ & NNFI & RMSEA \\
\hline Ethos and & Freely estimated & 42.82 & 19 & & 0.98 & 0.05 \\
Network & Constrained & 103.10 & 20 & $16.88^{*}$ & 0.93 & 0.10 \\
& & & & & & \\
Ethos and & Freely estimated & 109.60 & 19 & & 0.97 & 0.10 \\
Diaspora & Constrained & 130.40 & 20 & $33.99^{*}$ & 0.96 & 0.11 \\
& & & & & & \\
Ethos and & Freely estimated & 61.54 & 19 & & 0.98 & 0.07 \\
Attitude & Constrained & 98.32 & 20 & $32.54^{*}$ & 0.97 & 0.09 \\
Network and & Freely estimated & 32.35 & 19 & & 0.99 & 0.04 \\
Diaspora & Constrained & 83.15 & 20 & $47.50^{*}$ & 0.96 & 0.08 \\
& & & & & & \\
Network and & Freely estimated & 27.88 & 19 & & 0.99 & 0.03 \\
Attitude & Constrained & 109.20 & 20 & $33.58^{*}$ & 0.92 & 0.10 \\
Diaspora and & Freely estimated & 59.17 & 19 & & 0.98 & 0.07 \\
Attitude & Constrained & 89.45 & 20 & $64.61^{*}$ & 0.97 & 0.09 \\
\hline Nite
\end{tabular}

Note. ${ }^{*} p=0.001$.

NNFI = non-normed fit index; CFI = comparative fit index; RMSEA = root mean square of approximation; and RMSR = standardized root mean square residual

Associated with each measure of within and between subscale discrimination is a structure coefficient, a correlation. For calculating confidence bands these correlations are transformed, because, as Raykov 
(2011, p. 42) noted, the distribution of correlations is not symmetric it is skewed to the left/right in the case of positive/negative population correlation. With this in mind, a large sample confidence interval (CI) for a convergent or discriminant validity coefficient can be obtained by initially furnishing such a confidence interval (CI) for an appropriate monotonically increasing function of the coefficient such as Fisher's z-transformation.

This generates a close to normal distribution. Based on this finding, the confidence interval (CI) for the population-discriminant validity coefficients (Bonett \& Wright 2000; Raykov, 2011) was computed using this transformation. Table 4 reports the lower and upper bounds for each of these correlations. The $95 \%$ confidence bands are very tight, except for the diaspora subscale.

Table 4

Discriminant Validity and Confidence Band for Structural Coefficients, Total Sample N $=446$

\begin{tabular}{lcccccc}
\hline & \multicolumn{2}{c}{$\begin{array}{c}\text { Structural } \\
\text { Coefficient }\end{array}$} & \multicolumn{3}{c}{$\begin{array}{c}\text { 95\% Confidence Band for the } \\
\text { Population Correlation }\end{array}$} \\
\hline & $r$ & $S E$ & $\begin{array}{c}Z \\
\text { transform }\end{array}$ & $S E z$ & Lower & Upper \\
\hline Ethos & .50 & .05 & .55 & .10 & .41 & .59 \\
Network & .44 & .06 & .47 & .10 & .32 & .54 \\
Diaspora & .77 & .04 & 1.01 & .10 & .67 & .84 \\
Attitude & .52 & .05 & .58 & .10 & .41 & .62 \\
Ethos and Diaspora & .57 & .03 & .64 & .10 & .50 & .63 \\
Ethos and Attitude & .38 & .03 & .40 & 0 & .32 & .45 \\
Network and Ethos & .19 & .03 & .19 & 0 & .13 & .25 \\
Network and & & & & & & .26 \\
Diaspora & .20 & .04 & .20 & 0 & .13 & .26 \\
Network and Attitude & .07 & .03 & .07 & 0 & .01 & .13 \\
Diaspora and Attitude & .42 & .04 & .07 & .10 & .35 & .49 \\
\hline
\end{tabular}

\section{Hypotheses}

The investigation examined four subscales and the four items to evaluate the following hypotheses that are associated with the two alternative measurement models: Figure 1 shows the hypothesized, firstorder model of the four-construct structure of Greek-American ethnic identity, whereas Figure 2 shows the hypothesized, second-order model. 
Figure 1. Hypothesized Structure of Four-Construct Model of Greek American Ethnic Identity. The Adult Greek-American ethnic identity is a multidimensional structure that consists of four constructs: ethos, network, diaspora, and attitudes. The hypothesis of this first-order model is that each of these constructs converges on four manifest variables. Broadly, these variables capture the importance of the following attributes of Greek-American ethnic identity: language, politics, cultural and religious activities, social networks with other co-ethnics and as well as links to the ancestral land, and a person's stance regarding the use of Greek in liturgy and the teaching and learning of Greek in parochial schools.

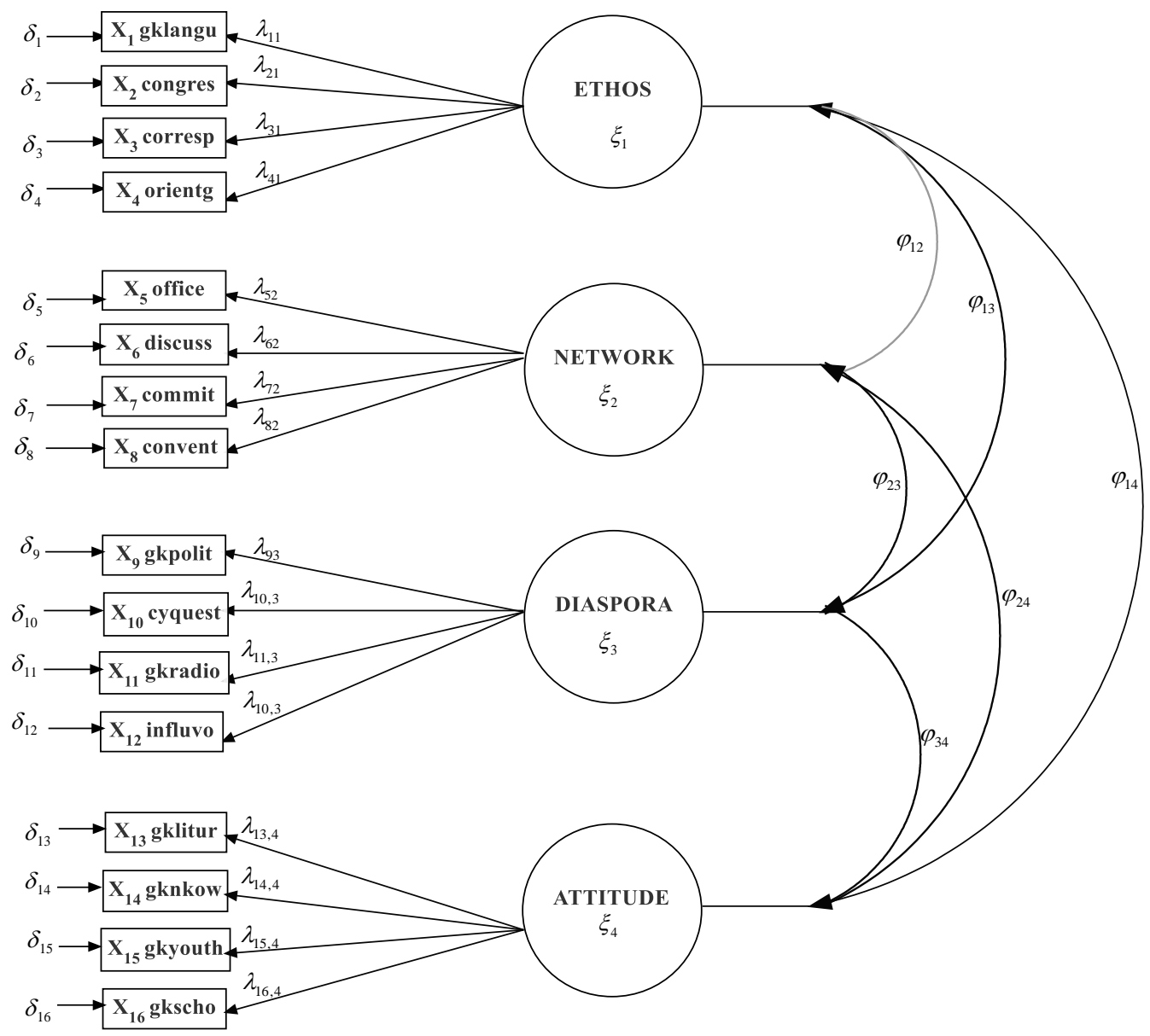

$$
X=\Lambda \xi+\delta, \quad \Sigma_{X X}=\Lambda_{X} \Phi \Lambda^{\prime}{ }_{X}+\Theta_{\delta}
$$


Figure 2. Hypothesized Second Order Model of Greek American Ethnic Identity. The hypothesis to be tested is that Greek-American ethnic identity is a single concept, and thus the second-order model provides a more parsimonious formulation and makes it easier to interpret the results.

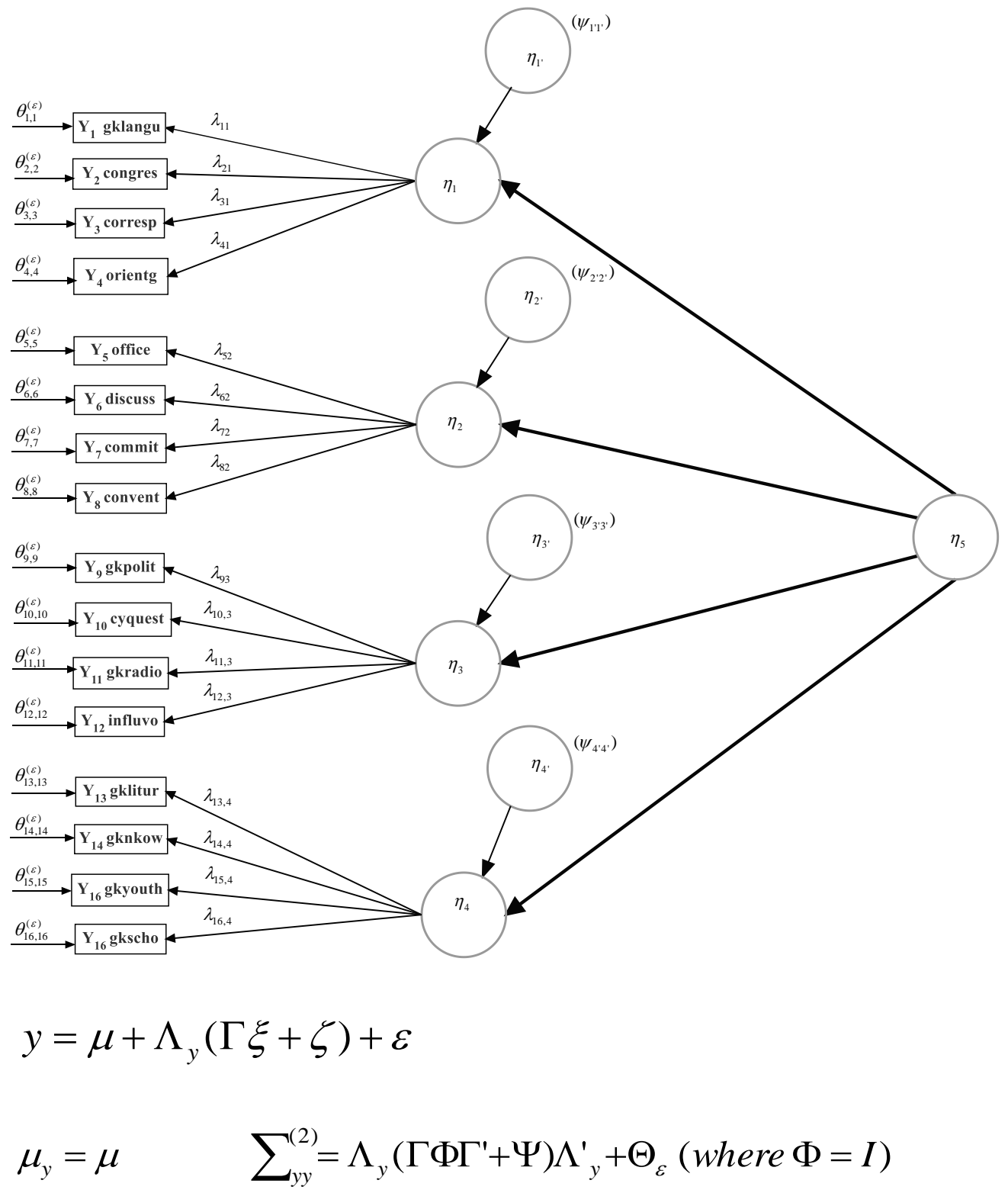

$\mathbf{H}_{1}$ : Subscale unidimensionality. Each of the latent variables: ethos, network, diaspora, and attitude converges on four respective manifest variables.

$\mathbf{H}_{2}$ : Four-factor correlated model. The correlated four-factor structure model fits the data significantly. 
$\mathbf{H}_{3}$ : Inter-factor correlations. The correlations among the four latent variables are significantly different from zero.

$\mathbf{H}_{4}$ : Second-order factor model. A single concept, AGIS, captures these inter-factor correlations among the four subscales. A confirmation of this proposition implies the existence of a single, second-order composite index of Greek-American ethnicity.

The next two hypotheses relate to the replicability of the AGIS.

$\mathrm{H}_{5}$ : Replication of the second order $\mathrm{H}_{\mathbf{4}}$ model. This model can be significantly replicated with increasingly smaller internal samples of $75 \%, 50 \%, 50 \%$ of the complement, and four- $25 \%$ samples (50\% divided into halves-random sample and complement sample).

$H_{6}$ : Comparisons of these seven samples to the total sample. These multisample analyses confirm that they are similar.

$\mathrm{H}_{7}$ : Cross validation analysis. Twenty-six cross-validations, each consisting of $50 \%$ model validation samples, with the complement samples of $50 \%$ replication samples, generate similar coefficients.

The last three hypotheses were designed to test the veracity of AGIS. In $\mathrm{H}_{5}$, the test involved the calculation of confidence band and the reliance on Pearson's $r$ to evaluate how loadings from AGIS models, that were fitted to smaller samples, approximate those from the total sample. $\mathrm{H}_{6}$ is a stricter way of assessing replicability of the scale, by testing in a multisample framework, the invariance of each sample to the total sample. Finally, $\mathrm{H}_{7}$ is the most restricted way of testing the replicability of AGIS by crossvalidation methodology.

\section{Hypothesis Testing}

The current investigation included seven hypotheses using procedures within confirmatory factor analysis (CFA) and multisample confirmatory factor analysis (MCFA). For $\mathrm{H}_{1}$, the subscale unidimensionality was tested by fitting a single latent variable (Steenkamp \& van Trijp, 1991).

For $\mathrm{H}_{2}$, a CFA correlated model, consisting of the four unidimensional subscales, was fitted to the data. In addition, unstandardized coefficients, standardized loadings, and the variance of each item were explained by the subscale.

The $\mathrm{H}_{3}$ entailed the analysis of the factor intercorrelations. Significant intercorrelations are one possible reason for the calibration of a secondorder factor model, if such a model is justified on theoretical grounds. As Sousa and West (2005, p. 473) stated, "second-order models are potentially applicable when (a) the lower order factors are substantially correlated with each other, and (b) there is a higher order factor that is hypothesized to account for the relations among the lower order factors."

For $\mathrm{H}_{4}$, a second-order factor model was fitted to the same data. In addition to testing the fit of the model, a target coefficient was calculated 
as the ratio of the chi-square of the first-order model to that of the higherorder model. Because this coefficient indicated the extent to which the higher-order factor model captured the covariation among the first-order factors (Marsh \& Hocevar 1985), a value greater than 0.75 was considered as another indicator of a second-order model. As Chen, Sousa, and West (2005, p. 472) observed, "in comparison to first-order models with correlated factors, second-order factor models can provide a more parsimonious and interpretable model when researchers hypothesize that higher order factors underlie their data."

The next two hypotheses $\left(\mathrm{H}_{5}\right.$ and $\left.\mathrm{H}_{6}\right)$ involved seven internally generated random samples via EQS 6.1 (Build 97) of increasingly smaller samples drawn from the 446 (AB) total surveys: (1) TQS-a three quarter sample of 334 observations, (2) AA-a random sample of 223 from AB, (3) $\mathrm{BB}-$ the complement random sample of 223 from $\mathrm{AB}$. Both $\mathrm{AA}$ and $\mathrm{BB}$ are further divided into two samples: AA into AA1 of 111 and AA2 of 112, and $\mathrm{BB}$ into $\mathrm{BB} 1$ of 111 and $\mathrm{BB} 2$ of 112, respectively.

In $\mathrm{H}_{5}$, a second-order model was fitted to the total sample. Specifically, the same AGIS model was fitted to each of these seven samples, consistent with the measures of fit to assess the fit of the models. The summary of the results included construct validity (construct and discriminant), maximum likelihood estimates, and reliabilities of loadings. Indeed, construct validity, as Floyd and Widaman (1995, p. 287) stated, "is supported if the factor structure of the scale is consistent with the constructs the instrument purports to measure." Finally, the intercorrelations were evaluated among the loadings (lower and second) by the use of a twotailed t-test. If these smaller samples reasonably mirror the total sample, then AGIS has been replicated. These tests constitute what Osborne and Fitzpatrick (2012) referred to as strong replicability.

Testing $\mathrm{H}_{6}$ involved some application of MCFA as applied by Seppala et al. (2009). For the total sample and one of the seven samples, the process entailed running a baseline (configural), multi-sample model and a constrained model with invariant first- and second-factor loadings. It is expected that the differences between corresponding fit statistic may not be significantly different from zero, and the p-value of the difference between the two chi-squares is larger than 0.05.

$\mathrm{H}_{7}$ posits that coefficients generated in half a sample are validated in the other half. Restating this proposition, Benson and Bandalos (1992, p. 465) wrote, "It was hypothesized that if the models obtained in the calibration sample were plausible, then not only should the overall test of fit be similar in the validation sample, but so should the parameter estimates." The data were split into two random halves, a calibration and a validation sample (Brown \& Cudeck, 1993; 1989). The parameters estimated using the calibration samples were used as fixed parameters in the validation sample and the model re-estimated. It was expected that the 
estimates were the same as in the calibration sample and the fits of the models were statistically the same. Cudeck and Browne (1983, p. 152) proposed a stricter procedure, "the double cross-validation where the process is reversed with validation sample now becomes the calibration sample." In this study, a single cross-validation with 26 pairs of validation and calibration sample sizes of 223 was generated using EQS 6.1. All the analytical methods used for testing the seven hypotheses above entailed some aspects of CFA and the use of combinations of fit indices.

\section{Fit Indices}

Where appropriate, a combination of some of the following measures of fit for evaluating the validity of each of the seven hypotheses was considered: a chi-square test statistic with a p-value greater than 0.05 , and incremental fit indices, non-normed fit index (NNFI), and comparative fit index (CFI). The NNFI compared the model to the null model of completely uncorrelated items, and CFI assessed overall improvement of a proposed model over a model in which the observed variables are uncorrelated. For both CFI and NNFI, a fit index greater than 0.95 indicated that the construct converged on the items. Also, the residualbased indices, root mean square of approximation (RMSEA) and the standardized root mean square residual (SRMR) were examined for fit. Other measures of fit included the normed chi-square ( $\chi^{2}$ divided by its degrees of freedom). The suggested acceptable levels for normed chisquare values ranged from two to as high as five (Schumacker 2010; Ullman, 2007). Finally, indices were used that reflect the difference between two, usually nested models. A significant chi-square difference $\left(\Delta \chi^{2}=\chi^{2}\right.$ con $-\chi^{2}$ baseline $)$ indicated that the unconstrained model fit the data more closely than the constrained model, and, therefore, the null hypothesis of factorial invariance was rejected. Because this difference had the same flaw as chi-square for large samples, other $\Delta$ goodness-of-fit indices such as $\triangle$ NNFI, $\triangle \mathrm{CFI}$, and $\triangle$ RMSEA were considered. The sensitivity of these and other indices were investigated extensively (Chen, Sousa, \& West, 2005; Cheung \& Rensvold, 2002; Fan \& Sivo, 2005, 2007, 2009). In this study, threshold values suggested by Fan and Sivo (2009) guided the analyses: $\triangle \mathrm{CFI}$ at $0.02, \triangle \mathrm{NNFI}$ at 0.025 , and $\triangle$ RMSEA at 0.020. As Fan and Sivo (2009, p. 63) stated, "in suggesting these threshold values, we chose a value higher than the $99^{\text {th }}$ percentile point of the empirical distribution of the $\Delta$ goodness-of-fit indexes under the true null hypothesis." 


\section{Results}

\section{Unidimensionality of Subscales $\left(\mathrm{H}_{1}\right)$}

For each of the four subscales, a unidimensional model was fitted to the data (Figure 3). The fact that the chi-square test statistics were nonsignificant for the network and diaspora subscales implied that the hypothesis of unidimensionality could not be rejected. Although the pvalues associated with the chi-square test statistics suggested that the ethos and attitude subscales may not be unidimensional, the large sample size of 446 taken together with other fit measures suggested that unidimensionality can be justified in both cases. The fit measured for ethos were: $\mathrm{NNFI}=0.97, \mathrm{CFI}=0.99, \mathrm{SRMR}=0.03$. The fit measured for attitude were: $\mathrm{NNFI}=0.98, \mathrm{CFI}=0.99, \mathrm{SRMR}=0.03$. The loadings for all four latent variables were significantly different from zero at $\alpha=0.05$. The average loadings were larger than 0.70 .

Figure 3. Unidimensionality of Subscales. The results of the analysis show that the four items converge significantly on their hypothesized constructs of ethos, network, diaspora, and attitude, and thus scale unidimensionality is preserved.

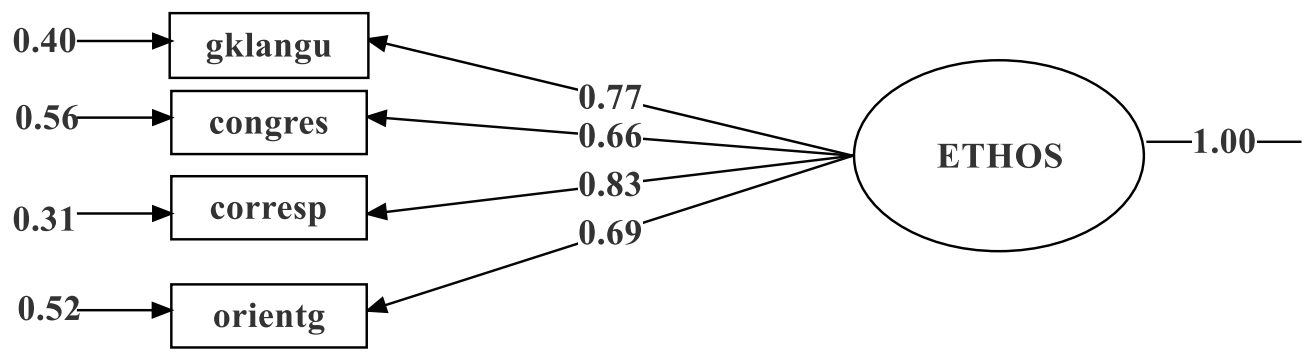

(a) Chi-Square $=21.672, \mathrm{df}=2, \mathrm{P}$-value $=0.004, \mathrm{RMSEA}=0.099$, $\mathrm{NNFI}=0.967, \mathrm{CFI}=0.989$, Standardized $\mathrm{RMR}=0.034$

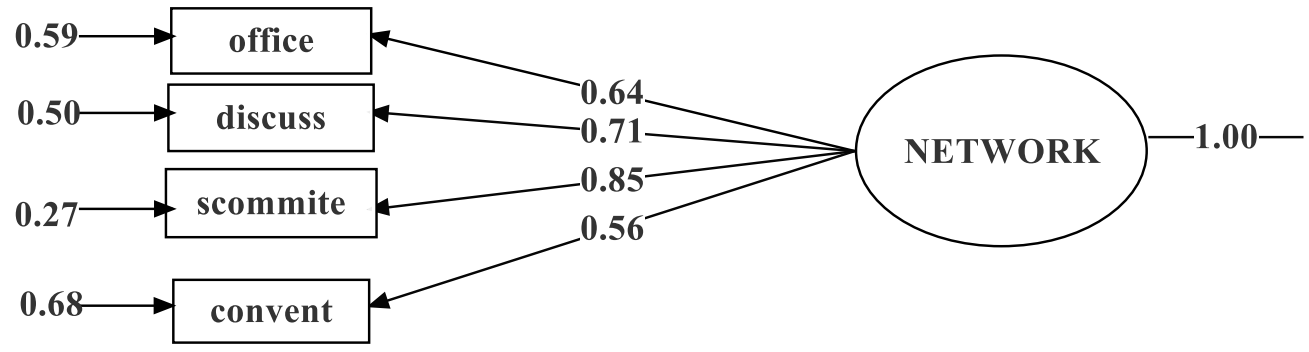

(b) Chi-Square $=1.218, \mathrm{df}=2, \mathrm{P}$-value $=0.709, \mathrm{RMSEA}=0.000$, $\mathrm{NNFI}=1.006, \mathrm{CFI}=1.000$, Standardized $\mathrm{RMR}=0.009$ 
Figure 3. Unidimensionality of Subscales (continued).

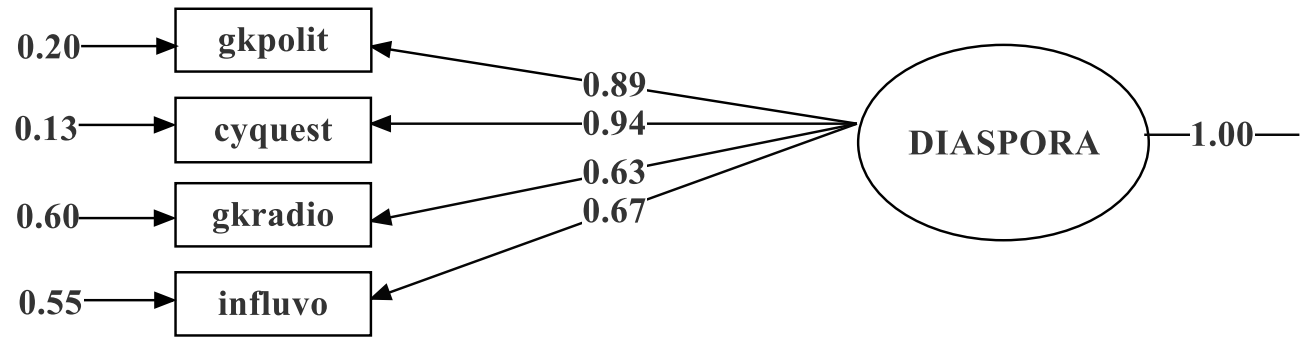

(c) Chi-Square $=10.374, \mathrm{df}=2, \mathrm{P}$-value $=0.058, \mathrm{RMSEA}=0.064$, $\mathrm{NNFI}=0.989, \mathrm{CFI}=0.996$, Standardized $\mathrm{RMR}=0.020$

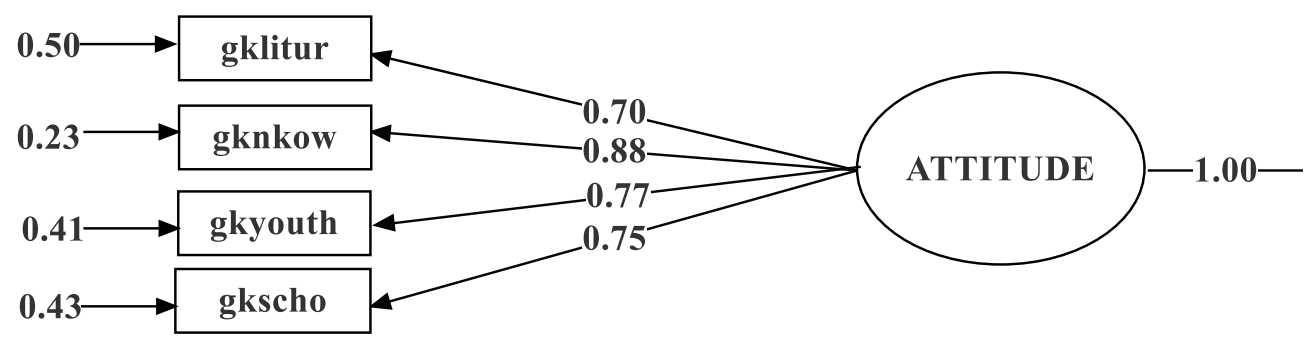

(d) Chi-Square $=17.542, \mathrm{df}=2, \mathrm{P}$-value $=0.000, \mathrm{RMSEA}=0.0 .87$, $\mathrm{NNFI}=0.979, \mathrm{CFI}=0.993$, Standardized RMR $=0.026$

\section{Testing AGIS Models on Total Sample $\left(\mathrm{H}_{2}-\mathbf{H}_{4}\right)$}

$\mathrm{H}_{2}$ : Based on the earlier precursor results on the convergent and discriminant nature of the four subscales, a four factor-correlated confirmatory factor analysis (CFA) model $\left(\mathrm{H}_{2}\right)$ was tested. Because of the large sample size, the Normal Theory of Weighted Least Squares chisquare of $454.21(d f=99)$ did not fit the data. Other measures of fit, however, indicated that the model fits the data $(\mathrm{NNFI}=0.98, \mathrm{CFI}=0.98$, RMSEA $=0.06$ with 90\% [0.049; 0.067], and SRMR $=0.06$ ). Table 5 summarizes the results of fitting this model. All the unstandardized coefficients were significantly different from zero at $\alpha=0.05$. Because an unstandardized coefficient was the change in the value of a variable for a unit change in the construct, a one-unit increase in the network construct, for example, was associated with a 1.24-unit increase in the level of participation in church or other organized committees. They are useful for comparing factor solutions across groups. In contrast, given that standardized coefficients were correlations of the items with the factor, they can be compared within the same factor. 
Table 5

Parameter Estimates and Standardized Solutions $(Z)$ for Total Sample

\begin{tabular}{|c|c|c|c|}
\hline Construct/Items & mle & $Z$ & $R^{2}$ \\
\hline \multicolumn{4}{|l|}{ Ethos } \\
\hline Importance of knowledge of Greek language & 1.00 & .71 & .50 \\
\hline Frequency of protesting to congress representatives & 1.11 & .79 & .62 \\
\hline Frequency of correspondence with Greece & 1.05 & .74 & .55 \\
\hline Degree of emotional orientation toward Greece & .97 & .69 & .48 \\
\hline \multicolumn{4}{|l|}{ Network } \\
\hline Office in church or Greek American organization & 1.00 & .66 & .44 \\
\hline Discussions about Greece & 1.10 & .72 & .52 \\
\hline Participation in church and organized committees & 1.25 & .82 & .67 \\
\hline Attendance at Greek American conventions & .87 & .58 & .33 \\
\hline \multicolumn{4}{|l|}{ Diaspora } \\
\hline Close watch on Greek politics & 1.00 & .88 & .77 \\
\hline Close watch on Cypriot politics & 1.05 & .92 & .85 \\
\hline Listens to Greek radio at home & .75 & .66 & .43 \\
\hline Effect of American Politics on voting choices & .80 & .70 & .49 \\
\hline \multicolumn{4}{|l|}{ Attitude } \\
\hline Greek should be emphasized in the liturgy & 1.00 & .72 & .52 \\
\hline Importance of Greek in interpersonal communication & 1.15 & .83 & .68 \\
\hline Greek American youth should learn Greek & 1.00 & .72 & .52 \\
\hline $\begin{array}{l}\text { Greek parochial schools should be in every } \\
\text { community }\end{array}$ & 1.02 & .75 & .55 \\
\hline
\end{tabular}

Note. All estimates are significantly different from zero at $\alpha=0.05$.

Rather than just summarize the factor inter-correlations, these correlations and their associated standard errors are reported in Table 6. The ratios between them indicated that all correlations were significantly different from zero $\left(\mathrm{H}_{3}\right)$. These significant, inter-subscale correlations may have reflected the possible existence of a second-order factor (Gorsuch, 1983, p. 255). 
Table 6

Composite Reliabilities of Subscales for Seven Subsamples

\begin{tabular}{lcccc}
\hline Sample & Ethos & Network & Diaspora & Attitude \\
\hline $\mathrm{AB}=(n=446)$ & .79 & .73 & .83 & .79 \\
$\mathrm{TQS}=75 \%(n=334)$ & .77 & .72 & .82 & .80 \\
$\mathrm{AA}=50 \%(n=223)$ & .79 & .74 & .83 & .80 \\
$\mathrm{BB}=50 \%(n=223)$ & .79 & .74 & .84 & .82 \\
$\mathrm{AA} 1=25 \%(n=111)$ of AA & .74 & .73 & .80 & .78 \\
$\mathrm{AA} 2=25 \%(n=112)$ of AA & .85 & .75 & .88 & .86 \\
$\mathrm{BB} 1=25 \%(n=111)$ of $\mathrm{BB}$ & .78 & .70 & .84 & .78 \\
$\mathrm{BB} 2=25 \%(\mathrm{n}=112)$ of BB & .82 & .71 & .84 & .82 \\
\hline
\end{tabular}

Note. AA splits into AA1 and its complement AA2. Similarly, BB splits into $\mathrm{BB} 1$ and its complement BB2.

A second-order factor model, $\mathrm{H}_{4}$ (Figure 2), fit the data as well based on the following indices: $\mathrm{NNFI}=0.98, \mathrm{CFI}=0.98$, RMSEA $=0.06$ with 90\% [0.05; 0.07] and SRMR $=0.06$. Table 7 reports additional results on parameters, standardized coefficients, and squared correlations. As expected, the lower-order parameter values were essentially the same as those for the correlated model. What is new were the second-order loadings of the four subscales to the AGIS index. These results highlight the impacts of the ethos and diaspora subscales on the AGIS. The target coefficient (at the bottom of Table 7) indicated that this higher-order AGIS accounted for over $97 \%$ of the covariation among the first-order AGIS factors. Based on this evidence and ease of interpretation of AGIS, the second-order AGIS was selected over the correlated first-order model. In a broader theoretical framework, Gorsuch (1983, p. 240) distinguished between the first-order factors (primary) and higher-order factors in this manner: "Primary factors are concerned with narrow areas of generalization where the accuracy is great. The higher-order factor reduces accuracy for an increase in the breadth of generalization." Elsewhere, Gorsuch (1983, p. 579) used the following analogy to differentiate between a first-order and a second-order model: "The first-order analysis is a closeup view that focuses on the details of the valleys and the peaks in mountains. The second-order analysis is like looking at the mountains at a greater distance, and yields a potentially different perspective on the mountains as constituents of a range."

\section{Replications of AGIS on Smaller Samples $\left(\mathrm{H}_{5}\right.$ and $\left.\mathrm{H}_{6}\right)$}

As discussed earlier, the replication analyses phase consisted of seven smaller random samples. For each of these internal samples, the convergent validities for the four subscales are calculated. Table 8 summarizes these calculations, together with the results for the total subscales for each sample converge on the appropriate measures. 
Table 7

Second-Order Model: Parameter Estimates and Standardized Solutions

\begin{tabular}{|c|c|c|c|}
\hline Construct/Items & mle & $R^{2}$ & $Z$ \\
\hline \multicolumn{4}{|l|}{ Ethos } \\
\hline $\mathrm{X} 1$ & 1.00 & .51 & 0.71 \\
\hline $\mathrm{X} 2$ & 1.10 & .61 & 0.79 \\
\hline $\mathrm{X}_{3}$ & 1.05 & .57 & 0.74 \\
\hline $\mathrm{X}_{4}$ & 0.97 & .48 & 0.69 \\
\hline \multicolumn{4}{|l|}{ Network } \\
\hline $\mathrm{X}_{5}$ & 1.00 & .44 & 0.66 \\
\hline X6 & 1.10 & .52 & 0.72 \\
\hline $\mathrm{X}_{7}$ & 1.25 & .67 & 0.82 \\
\hline $\mathrm{X} 8$ & 0.87 & .33 & 0.58 \\
\hline \multicolumn{4}{|l|}{ Diaspora } \\
\hline X9 & 1.00 & .77 & 0.88 \\
\hline $\mathrm{X} 10$ & 1.05 & .85 & 0.92 \\
\hline $\mathrm{X} 11$ & 0.75 & .43 & 0.66 \\
\hline $\mathrm{X} 12$ & 0.80 & .49 & 0.70 \\
\hline \multicolumn{4}{|l|}{ Attitude } \\
\hline $\mathrm{X} 13$ & 1.00 & .51 & 0.72 \\
\hline $\mathrm{X} 14$ & 1.16 & .69 & 0.83 \\
\hline $\mathrm{X} 15$ & 1.02 & .53 & 0.72 \\
\hline $\mathrm{X} 16$ & 1.03 & .54 & 0.75 \\
\hline \multicolumn{4}{|l|}{ Second-Order Coefficients } \\
\hline Ethos & 0.71 & 1.00 & \\
\hline Network & -0.03 & & \\
\hline Diaspora & 0.25 & .14 & \\
\hline Attitude & -0.04 & & \\
\hline Target Coefficient (246.05/251.29) & 0.79 & .82 & \\
\hline
\end{tabular}

Note. All estimates are significantly different from zero at $\alpha=0.05$ and $\mathrm{t}$-values are in parentheses.

The reproducibility of the second-order AGIS model $\left(\mathrm{H}_{5}\right)$ was tested by fitting the same model to each of the seven internally generated smaller samples (Table 8). The normed Chi-square values ranged from 1.25 to 3.12 with a mean of 2.41. These values were within the expected range for concluding that the models fit the selected sample sizes. The values for the NNFI and CFI indices suggested similar conclusions, given that the NNFI values ranged from 0.95 to 0.99 , and the CFI values ranged from 0.96 to 0.99. In addition, the RMSEA values indicated that this conclusion was plausible. They ranged from 0.04 to 0.08 . Based on these thresholds for 
the fit indices discussed earlier, the data for all these samples fit the second-order AGIS model well.

Table 8

Fit Indices for Various Sample Sizes of the Second-Order Confirmatory Model

\begin{tabular}{|c|c|c|c|c|c|c|}
\hline Description of Sample & $n$ & $\chi^{2} / d f$ & NNFI & CFI & RMSEA & ECVI \\
\hline Total Sample & 446 & 2.49 & .98 & .98 & $.06^{*}$ & $0.72^{*}$ \\
\hline 75\% (random) & 334 & 2.99 & .96 & .96 & .08 & 1.11 \\
\hline A: Random Half Sample & 223 & 2.49 & .97 & .98 & .06 & 1.08 \\
\hline B: Random Half Sample & 223 & 3.12 & .98 & .98 & .06 & 1.08 \\
\hline $\begin{array}{l}\text { A1: Random Half Sample of A } \\
\text { (one fourth of original sample) }\end{array}$ & 111 & 2.97 & .95 & .96 & .08 & 2.24 \\
\hline $\begin{array}{l}\text { A2: Random Half Sample of A } \\
\quad \text { (one fourth of original sample) }\end{array}$ & 112 & 2.64 & .96 & .97 & .07 & 2.01 \\
\hline $\begin{array}{l}\text { B1: Random Half Sample of B } \\
\text { (one fourth of original sample) }\end{array}$ & 111 & 1.33 & .98 & .98 & .06 & 1.96 \\
\hline $\begin{array}{l}\text { B2: Random Half Sample of B } \\
\text { (one fourth of original sample) }\end{array}$ & 112 & 2.21 & .99 & .99 & .04 & 1.76 \\
\hline \multicolumn{7}{|c|}{$\begin{array}{l}\text { Note. * o 9o Percent Confidence Interval for all values under RMSEA and ECVI. } \\
\text { NNFI = nonnormed Fit Index; CFI = comparative fit index; RMSEA = root mean } \\
\text { square of approximation; ECVI = expected cross validation index. }\end{array}$} \\
\hline \multicolumn{7}{|c|}{$\begin{array}{l}\text { For these sample sizes, the four-factor second-order confirmatory } \\
\text { AGIS model converged, and the loadings for the lower- and higher-order } \\
\text { factors were all significant at the o.o1 level (Table } 9 \text { and Table 10). } \\
\text { Consistently, the loadings were highest for the ethos and diaspora } \\
\text { subscales. Finally, the ability of smaller internal samples to replicate the } \\
\text { model was summarized in the correlations of the loadings generated by } \\
\text { different samples. These significant correlations provide another } \\
\text { perspective about the reproducibility of the AGIS scale by smaller internal } \\
\text { samples as hypothesized in } \mathrm{H}_{5} \text { (Table 11). }\end{array}$} \\
\hline
\end{tabular}




\section{GREEK-AMERICAN IDENTITY SCALE}

Table 9

First-Order Factor Loadings and Associated Squared Multiple Correlations

\begin{tabular}{|c|c|c|c|c|c|c|c|c|}
\hline Construct/Items & $\mathrm{A}$ & TQS & $\mathrm{AA}$ & $\mathrm{BB}$ & AA1 & AA2 & $\mathrm{BB} 1$ & $\mathrm{BB} 2$ \\
\hline \multicolumn{9}{|l|}{ Ethos } \\
\hline \multirow{2}{*}{$\mathrm{X} 1$} & 1.00 & 1.00 & 1.00 & 1.00 & 1.00 & 1.00 & 1.00 & 1.00 \\
\hline & -0.50 & -0.46 & -0.47 & -0.57 & -0.49 & -0.45 & -0.53 & -0.61 \\
\hline \multirow{2}{*}{$\mathrm{X} 2$} & 1.11 & 1.17 & 1.14 & 0.98 & 1.15 & 1.05 & 0.96 & 0.99 \\
\hline & -0.62 & -0.64 & -0.60 & -0.55 & -0.65 & -0.50 & -0.51 & -0.60 \\
\hline \multirow{2}{*}{$\mathrm{X}_{3}$} & 1.05 & 1.07 & 1.12 & 0.98 & 0.98 & 1.09 & 0.93 & 1.01 \\
\hline & -0.55 & -0.54 & -0.58 & -0.55 & -0.47 & -0.54 & -0.47 & -0.62 \\
\hline \multirow{2}{*}{$\mathrm{X}_{4}$} & 0.97 & 1.00 & 1.04 & 1.01 & 0.97 & 0.90 & 0.94 & 1.04 \\
\hline & -0.48 & -0.47 & -0.51 & -0.59 & -0.46 & -0.36 & -0.48 & -0.66 \\
\hline \multicolumn{9}{|l|}{ Network } \\
\hline \multirow{2}{*}{$\mathrm{X}_{5}$} & 1.00 & 1.00 & 1.00 & 1.00 & 1.00 & 1.00 & 1.00 & 1.00 \\
\hline & -0.44 & -0.45 & -0.41 & -0.37 & -0.43 & -0.39 & -0.37 & -0.40 \\
\hline \multirow{2}{*}{ X6 } & 1.10 & 1.00 & 1.03 & 1.25 & 1.14 & 1.07 & 1.27 & 1.16 \\
\hline & -0.52 & -0.46 & -0.44 & -0.56 & -0.57 & -0.45 & -0.55 & -0.54 \\
\hline \multirow{2}{*}{$\mathrm{X}_{7}$} & 1.24 & 1.17 & 1.23 & 1.28 & 1.10 & 1.20 & 1.32 & 1.13 \\
\hline & -0.68 & -0.62 & -0.62 & -0.60 & -0.53 & -0.56 & -0.62 & -0.52 \\
\hline \multirow{2}{*}{$\mathrm{X} 8$} & 0.87 & 0.95 & 1.00 & 1.02 & 1.02 & 0.98 & 1.20 & 0.81 \\
\hline & -0.33 & -0.41 & -0.41 & -0.38 & -0.46 & -0.37 & -0.53 & -0.26 \\
\hline \multicolumn{9}{|l|}{ Diaspora } \\
\hline \multirow{2}{*}{ X9 } & 1.00 & 1.00 & 1.00 & 1.00 & 1.00 & 1.00 & 1.00 & 1.00 \\
\hline & -0.77 & -0.69 & -0.71 & -0.78 & -0.71 & -0.73 & -0.88 & -0.68 \\
\hline \multirow{2}{*}{$\mathrm{X} 10$} & 1.05 & 1.09 & 1.07 & 1.06 & 1.07 & 1.06 & 1.04 & 1.07 \\
\hline & -0.85 & -0.81 & -0.81 & -0.88 & -0.81 & -0.87 & -0.95 & -0.77 \\
\hline \multirow{2}{*}{$\mathrm{X} 11$} & 0.75 & 0.78 & 0.73 & 0.71 & 0.85 & 0.57 & 0.66 & 0.78 \\
\hline & -0.43 & -0.42 & -0.38 & -0.39 & -0.51 & -0.24 & -0.38 & -0.42 \\
\hline \multirow{2}{*}{$\mathrm{X} 12$} & 0.80 & 0.79 & 0.74 & 0.71 & 0.75 & 0.81 & 0.73 & 0.71 \\
\hline & -0.49 & -0.43 & -0.39 & -0.40 & -0.42 & -0.48 & -0.47 & -0.34 \\
\hline
\end{tabular}


Table 9 (continued)

\begin{tabular}{lrrrrrrrr}
\hline Construct/Items & A & TQS & AA & BB & AA1 & AA2 & BB1 & BB2 \\
\hline Attitude & & & & & & & & \\
\hline \multirow{2}{*}{ X13 } & 1.00 & 1.00 & 1.00 & 1.00 & 1.00 & 1.00 & 1.00 & 1.00 \\
& -0.52 & -0.42 & -0.45 & -0.46 & -0.57 & -0.43 & -0.51 & -0.43 \\
X14 & 1.14 & 1.26 & 1.19 & 1.29 & 1.06 & 1.21 & 1.32 & 1.22 \\
& -0.68 & -0.66 & -0.63 & -0.77 & -0.63 & -0.63 & -0.89 & -0.66 \\
X15 & 1.00 & 1.03 & 1.01 & 1.14 & 0.91 & 0.88 & 1.16 & 1.10 \\
& -0.52 & -0.44 & -0.45 & -0.60 & -0.47 & -0.33 & -0.68 & -0.52 \\
X16 & 1.02 & 1.08 & 0.99 & 1.13 & 0.87 & 1.03 & 1.00 & 1.25 \\
& -0.55 & -0.49 & -0.44 & -0.59 & -0.42 & -0.45 & -0.51 & -0.68 \\
\hline
\end{tabular}

Note: IItems in Table 9 align with items in Table 7.

${ }^{2}$ The first item of each factor was constrained to one.

3Column headings: A is the total sample, $n=446$. TQS $=\mathrm{a} 75 \%$ sample of $n=334$ observations; $\mathrm{AA}=\mathrm{a}$ random sample of $50 \%, n=223$ from $\mathrm{AB}$; $\mathrm{BB}=$ the complement random sample of $50 \%, n=223$ from $\mathrm{AB}$. Both AA and $\mathrm{BB}$ are further divided in two samples: AA into two random samples: AA1, a sample of $n$ $=111$ and AA2, a sample of $n=112$, and BB into two random samples: BB1 a sample of $n=111$ and BB2 a sample of $n=112$, respectively.

Table 10

Second-Order Coefficients for Four Subscales

\begin{tabular}{lcccccccc}
\hline Sample & \multicolumn{2}{c}{ Ethos } & \multicolumn{2}{c}{ Network } & \multicolumn{2}{c}{ Diaspora } & \multicolumn{2}{c}{ Attitude } \\
\hline & $\lambda$ & $S E$ & $\lambda$ & $S E$ & $\lambda$ & $S E$ & $\lambda$ & $S E$ \\
\hline A & .71 & .03 & .24 & .04 & .79 & .03 & .53 & .04 \\
TQS & .68 & .04 & .26 & .04 & .76 & .04 & .41 & .05 \\
AA & .69 & .02 & .24 & .05 & .75 & .03 & .43 & .05 \\
BB & .74 & .04 & .29 & .06 & .80 & .07 & .49 & .05 \\
AA1 & .74 & .07 & .24 & .07 & .76 & .07 & .41 & .08 \\
AA2 & .68 & .04 & .14 & .07 & .74 & .05 & .37 & .07 \\
BB1 & .74 & .06 & .22 & .08 & .83 & .05 & .49 & .08 \\
BB2 & .76 & .05 & .36 & .08 & .75 & .07 & .46 & .08 \\
\hline$N 07$ & & & .07
\end{tabular}

Note. A is the total sample, $n=446$. TQS $=\mathrm{a} 75 \%$ sample of $n=334$ observations; $\mathrm{AA}=\mathrm{a}$ random sample of $50 \%, n=223$ from $\mathrm{AB} ; \mathrm{BB}=$ the complement random sample of $50 \%, n=223$ from $\mathrm{AB}$. Both $\mathrm{AA}$ and $\mathrm{BB}$ are further divided in two samples: AA into two random samples: AA1, a sample of $n=111$ and AA2, a sample of $n=112$, and BB into two random samples: BB1 a sample of $n=111$ and BB2 a sample of $n=112$, respectively. 
Table 11

Multiple Correlations of the Factor Loadings (First and Second order) for Subsamples

\begin{tabular}{|c|c|c|c|c|c|c|c|c|}
\hline Sample Sizes & 1 & 2 & 3 & 4 & 5 & 6 & 7 & 8 \\
\hline 1. $A=446$ & 1 & & & & & & & \\
\hline $\begin{array}{l}2 . \mathrm{TQS}=75 \% \\
(334)\end{array}$ & $.98^{* *}$ & 1 & & & & & & \\
\hline $\begin{array}{l}3 . \mathrm{AA}=50 \% \\
(223)\end{array}$ & $.98^{* *}$ & $.99^{* *}$ & 1 & & & & & \\
\hline $\begin{array}{l}4 . \mathrm{BB}=50 \% \\
(223)\end{array}$ & $.95^{* *}$ & $.94^{* *}$ & $.94^{* *}$ & 1 & & & & \\
\hline $\begin{array}{l}\text { 5.AA1 }=25 \% \\
(111) 1 / 2 \text { of } \mathrm{AA}\end{array}$ & $.94^{* *}$ & $.94^{* *}$ & $.96^{* *}$ & $.90^{* *}$ & 1 & & & \\
\hline $\begin{array}{l}\text { 6.AA2 }=25 \% \\
(112) 1 / 2 \text { of } A A\end{array}$ & $.91^{* *}$ & $.90^{* *}$ & $.90^{* *}$ & $.81^{* *}$ & $.77^{* *}$ & 1 & & \\
\hline $\begin{array}{l}7 . \mathrm{BB} 1=25 \% \\
(111)^{1 / 2} \text { of } \mathrm{BB}\end{array}$ & $.92^{* *}$ & $.90^{* *}$ & $.92^{* *}$ & $.98^{* *}$ & $.89^{* *}$ & $.91^{* *}$ & 1 & \\
\hline $\begin{array}{l}8 . \mathrm{BB} 2=25 \% \\
(112) 1 / 2 \text { of } \mathrm{BB}\end{array}$ & $.93^{* *}$ & $.94^{* *}$ & $.92^{* *}$ & $.96^{* *}$ & $.86^{* *}$ & $.91^{* *}$ & $.88^{* *}$ & 1 \\
\hline
\end{tabular}

Note. ${ }^{* *}$ Correlation is significant at the 0.01 level (two-tailed).

The final reproducibility evaluation of AGIS involved some analysis of invariance between the total sample and each of the seven internally generated smaller samples $\left(\mathrm{H}_{6}\right)$. Table 12 summarizes this multi-sample confirmatory factor analysis (MCFA) for the lower- and second-order loadings. The p-values, based on the difference in the chi-square generated by the baseline and invariant models, indicated that these loadings were not statistically different from loadings of the total sample. The small differences in other fit indices (RMSEA, NNFI, CFI, and RMSR) for each model were other indicators of invariance between baseline models and corresponding invariant models.

\section{Cross-Validations of AGIS on Smaller Samples $\left(\mathrm{H}_{7}\right)$}

The most rigorous evaluation of the robustness of the AGIS model was by cross-validation analysis $\left(\mathrm{H}_{7}\right)$ discussed earlier. The results included the scaled chi-square and three $\Delta$ goodness-of-fit indices ( $\Delta$ RMSEA, $\Delta$ NNFI, $\Delta$ CFI) for 26 calibration-validation models (Table 13). Based on 
the thresholds suggested earlier for these $\Delta$ goodness-of-fit indexes, the AGIS is validated in 25 out of 26 samples.

Table 12

Second-Order Multisample Comparisons Internal to Total Sample:

Baseline to Invariant Loadings

\begin{tabular}{|c|c|c|c|c|c|c|c|}
\hline \multirow[t]{2}{*}{$\begin{array}{c}\text { Target } \\
\text { Samples }\end{array}$} & \multirow[t]{2}{*}{ Models } & \multicolumn{2}{|c|}{ Fit Indices } & \multirow[b]{2}{*}{ RMSEA } & \multirow[b]{2}{*}{ NNFI } & \multirow[b]{2}{*}{ CFI } & \multirow[b]{2}{*}{ RMSR } \\
\hline & & $X^{2}$ & $d f$ & & & & \\
\hline \multirow[t]{3}{*}{ A and TQS } & Baseline & 982.67 & 204 & .07 & .96 & .98 & .07 \\
\hline & Invariant & 989.32 & 220 & .07 & .97 & .98 & .07 \\
\hline & $\Delta \chi^{2} p=.979$ & 6.65 & 16 & .00 & .01 & .00 & .00 \\
\hline \multirow[t]{3}{*}{$\mathrm{A}$ and $\mathrm{AA}$} & Baseline & 789.74 & 206 & .60 & .98 & .98 & .07 \\
\hline & Invariant & 796.51 & 221 & .06 & .98 & .98 & .07 \\
\hline & $\Delta \chi^{2} p=.977$ & 6.77 & 16 & .00 & .00 & .00 & .00 \\
\hline \multirow[t]{3}{*}{$A$ and $B B$} & Baseline & 787.58 & 205 & .06 & .98 & .98 & .08 \\
\hline & Invariant & 790.82 & 221 & .06 & .98 & .98 & .08 \\
\hline & $\Delta \chi^{2} p=1.00$ & 3.24 & 16 & .00 & .00 & .00 & .00 \\
\hline \multirow[t]{3}{*}{ A and AA1 } & Baseline & 710.81 & 205 & .06 & .98 & .98 & .08 \\
\hline & Invariant & 716.73 & 221 & .06 & .98 & .98 & .09 \\
\hline & $\Delta \chi^{2} p=.99$ & $5 \cdot 91$ & 16 & .00 & .00 & .00 & .01 \\
\hline \multirow[t]{3}{*}{$\mathrm{A}$ and $\mathrm{AA} 2$} & Baseline & 748.54 & 205 & .06 & .98 & .98 & .06 \\
\hline & Invariant & 773.00 & 221 & .06 & .98 & .98 & .06 \\
\hline & $\Delta \chi^{2} p=.08$ & 24.46 & 16 & .00 & .00 & .00 & .00 \\
\hline \multirow[t]{3}{*}{$\mathrm{A}$ and $\mathrm{BB} 1$} & Baseline & 706.13 & 205 & .06 & .98 & .98 & .06 \\
\hline & Invariant & 717.27 & 221 & .06 & .96 & .98 & .06 \\
\hline & $\Delta \chi^{2} p=.80$ & 11.15 & 16 & .00 & .02 & .00 & .00 \\
\hline \multirow[t]{3}{*}{$\mathrm{A}$ and $\mathrm{BB} 2$} & Baseline & 752.94 & 205 & .06 & .98 & .98 & .06 \\
\hline & Invariant & 761.11 & 221 & .06 & .98 & .98 & .06 \\
\hline & $\Delta \chi^{2} p=.94$ & 8.17 & 16 & .00 & .00 & .00 & .00 \\
\hline
\end{tabular}

Note. A is the total sample, $n=446$. TQS $=$ a $75 \%$ sample of $n=334$ observations; $\mathrm{AA}=\mathrm{a}$ random sample of $50 \%, n=223$ from $\mathrm{AB} ; \mathrm{BB}=$ the complement random sample of $50 \%, n=223$ from $\mathrm{AB}$. Both $\mathrm{AA}$ and $\mathrm{BB}$ are further divided in two samples: AA into two random samples: AA1, a sample of $n=111$ and AA2, a sample of $n=112$, and BB into two random samples: BB1 a sample of $n=111$ and $\mathrm{BB} 2$ a sample of $n=112$, respectively. NNFI $=$ non-normed fit index; $\mathrm{CFI}=$ comparative fit index; RMSEA = root mean square of approximation; and RMSR $=$ standardized root mean square residual. 


\section{GREEK-AMERICAN IDENTITY SCALE}

Table 13

Simple Cross Validation. Selected Goodness of Fit Indices and Associated Change

\begin{tabular}{|c|c|c|c|c|c|c|c|c|c|c|c|}
\hline \multirow{2}{*}{$\frac{\text { Samples }}{\mathrm{C}^{1} \text { and } \mathrm{V}}$} & \multicolumn{2}{|c|}{ Scaled $\chi^{2}$} & \multicolumn{2}{|c|}{ RMSEA } & \multicolumn{2}{|c|}{ NNFI } & \multicolumn{2}{|c|}{ CFI } & \multirow{2}{*}{$\frac{\Delta \text { RMSEA }^{3}}{\mathrm{CV}^{2}}$} & \multirow{2}{*}{$\frac{\Delta \mathrm{NNFI}}{\mathrm{CV}}$} & \multirow{2}{*}{$\frac{\Delta \mathrm{CFI}}{\mathrm{CV}}$} \\
\hline & $\mathrm{C}$ & $\mathrm{V}$ & $\mathrm{C}$ & $\mathrm{V}$ & $\mathrm{C}$ & $\mathrm{V}$ & $\mathrm{C}$ & $\mathrm{V}$ & & & \\
\hline $\mathrm{C}_{1}$ and $\mathrm{V}_{1}$ & 3.12 & 2.64 & 0.06 & 0.05 & 0.97 & 0.99 & 0.98 & 0.99 & .01 & .01 & .01 \\
\hline $\mathrm{C}_{2}$ and $\mathrm{V}_{2}$ & 3.40 & 2.52 & 0.06 & 0.06 & 0.98 & 0.98 & 0.98 & 0.98 & .00 & .00 & .00 \\
\hline $\mathrm{C}_{3}$ and $\mathrm{V}_{3}$ & 3.37 & 5.46 & 0.06 & 0.06 & 0.97 & 0.98 & 0.98 & 0.98 & .00 & .00 & .00 \\
\hline $\mathrm{C}_{4}$ and $\mathrm{V}_{4}$ & 2.94 & 3.51 & 0.06 & 0.05 & 0.98 & 0.98 & 0.98 & 0.98 & .01 & .00 & .00 \\
\hline $\mathrm{C}_{5}$ and $\mathrm{V}_{5}$ & 3.03 & 4.31 & 0.06 & 0.06 & 0.98 & 0.98 & 0.98 & 0.98 & .00 & .00 & .00 \\
\hline $\mathrm{C}_{6}$ and $\mathrm{V}_{6}$ & 3.00 & 3.90 & 0.05 & 0.06 & 0.98 & 0.98 & 0.99 & 0.98 & .01 & .00 & .01 \\
\hline $\mathrm{C}_{7}$ and $\mathrm{V}_{7}$ & 2.50 & 4.71 & 0.04 & 0.06 & 0.99 & 0.98 & 0.99 & 0.98 & .02 & .01 & .01 \\
\hline $\mathrm{C}_{8}$ and $\mathrm{V}_{8}$ & 3.32 & 3.33 & 0.07 & 0.05 & 0.99 & 0.97 & 0.98 & 0.99 & .02 & .01 & .01 \\
\hline $\mathrm{C}_{9}$ and $\mathrm{V}_{9}$ & 3.27 & 3.71 & 0.06 & 0.06 & 0.97 & 0.98 & 0.98 & 0.98 & .00 & .00 & .00 \\
\hline $\mathrm{C}_{10}$ and $\mathrm{V}_{10}$ & 3.10 & 4.12 & 0.06 & 0.06 & 0.98 & 0.98 & 0.98 & 0.98 & .00 & .00 & .00 \\
\hline $\mathrm{C}_{11}$ and $\mathrm{V}_{11}$ & 3.18 & 2.97 & 0.06 & 0.05 & 0.98 & 0.98 & 0.98 & 0.98 & .01 & .00 & .00 \\
\hline $\mathrm{C}_{12}$ and $\mathrm{V}_{12}$ & 3.16 & 3.58 & 0.07 & 0.06 & 0.97 & 0.98 & 0.97 & 0.98 & .01 & .01 & .01 \\
\hline $\mathrm{C}_{13}$ and $\mathrm{V}_{13}$ & 3.41 & 3.24 & 0.07 & 0.07 & 0.97 & 0.97 & 0.98 & 0.97 & .00 & .00 & .00 \\
\hline $\mathrm{C}_{14}$ and $\mathrm{V}_{14}$ & 3.14 & 4.96 & 0.06 & 0.06 & 0.98 & 0.98 & 0.98 & 0.98 & .00 & .00 & .00 \\
\hline $\mathrm{C}_{15}$ and $\mathrm{V}_{15}$ & 3.16 & 2.69 & 0.06 & 0.05 & 0.97 & 0.98 & 0.98 & 0.99 & .01 & .01 & .01 \\
\hline $\mathrm{C}_{16}$ and $\mathrm{V}_{16}$ & 2.59 & 2.24 & 0.05 & 0.04 & 0.98 & 0.99 & 0.98 & 0.99 & .01 & .01 & .01 \\
\hline $\mathrm{C}_{17}$ and $\mathrm{V}_{17}$ & 2.89 & 2.50 & 0.06 & 0.05 & 0.98 & 0.98 & 0.98 & 0.98 & .01 & .00 & .00 \\
\hline $\mathrm{C}_{18}$ and $\mathrm{V}_{18}$ & 2.40 & 3.19 & 0.04 & 0.07 & 0.99 & 0.97 & 0.99 & 0.97 & .03 & .02 & .02 \\
\hline $\mathrm{C}_{19}$ and $\mathrm{V}_{19}$ & 2.75 & 3.19 & 0.06 & 0.06 & 0.98 & 0.98 & 0.98 & 0.98 & .01 & .00 & .00 \\
\hline $\mathrm{C}_{20}$ and $\mathrm{V}_{20}$ & 3.40 & 2.73 & 0.07 & 0.05 & 0.98 & 0.98 & 0.98 & 0.98 & .01 & .00 & .00 \\
\hline $\mathrm{C}_{21}$ and $\mathrm{V}_{21}$ & 3.10 & 2.82 & 0.06 & 0.06 & 0.98 & 0.98 & 0.98 & 0.98 & .00 & .00 & .01 \\
\hline $\mathrm{C}_{22}$ and $\mathrm{V}_{22}$ & 3.48 & 2.73 & 0.07 & 0.05 & 0.97 & 0.98 & 0.97 & 0.98 & .02 & .02 & .01 \\
\hline $\mathrm{C}_{23}$ and $\mathrm{V}_{23}$ & 3.06 & 3.13 & 0.06 & 0.06 & 0.98 & 0.98 & 0.98 & 0.98 & .01 & .00 & .00 \\
\hline $\mathrm{C}_{24}$ and $\mathrm{V}_{24}$ & 3.24 & 3.36 & 0.06 & 0.07 & 0.98 & 0.97 & 0.98 & 0.97 & .01 & .01 & .01 \\
\hline $\mathrm{C}_{25}$ and $\mathrm{V}_{25}$ & 3.01 & 3.05 & 0.06 & 0.06 & 0.98 & 0.98 & 0.98 & 0.98 & .00 & .00 & .00 \\
\hline $\mathrm{C}_{26}$ and $\mathrm{V}_{26}$ & 3.20 & 2.99 & 0.06 & 0.06 & 0.98 & 0.98 & 0.98 & 0.98 & .00 & .00 & .00 \\
\hline
\end{tabular}

Notes. ${ }^{1} \mathrm{C}$ is for Calibration and $\mathrm{V}$ is for Validation of Samples of Size 223 for 26 different samples.

${ }^{2} \mathrm{CV}$ equals the absolute difference between $\mathrm{C}$ and $\mathrm{V}$.

${ }^{3} \Delta$ RMSEA values greater than. 020 are in bold.

\section{Discussion}

Previous research has developed scales for the measurement of ethnic identity, especially as it pertains to adolescents. In contrast to these studies, the current investigation presents a scale for the measurement of 
ethnic identity among adults: AGIS. In addition, this scale is ethnic-group specific, because it takes into consideration the most important characteristics of Greek-Americans: the role of language, the Greek Orthodox Church, and the family. The AGIS is a theoretically derived and psychometrically validated scale. This study is situated under the broader theoretical framework of acculturation, a commonly used theme in the analysis of ethnic identity.

The AGIS tested the theory that Greek-American ethnic identity has an underlying structure that consists of three internal factors, as well as one external factor. The internal component converges on the subscales of ethos, network, and diaspora, whereas the external component converges on the attitude subscale. Four measurement variables converged on each of the four constructs, for a total of 16 measurement variables. Four subscales and the four items were used to evaluate the seven hypotheses as associated with two alternative models, the first-order model and the second-order model. Specifically: the ethos factor converges on four measurement variables that capture the importance of language and the role of politics as important in fostering emotional orientation toward the ancestral land; network factor converges on four observed variables that describe a Greek-American's participation in cultural and religious activities of great relevance to the group; diaspora factor converges on four measurement variables that reflect the dynamics of the linkages among members of the diasporic community and the dominant host culture, as well as linkages with the ancestral land; and lastly, the attitude factor converges on four manifest variables that express the individual's evaluative response to the use of the Greek language in liturgy, as well as the teaching and learning of Greek language in parochial schools.

The findings of the study demonstrate that the four items converge significantly on their hypothesized constructs, and, thus, scale unidimensionality is preserved $\left(\mathrm{H}_{1}\right)$. A Confirmatory Factor Analysis (CFA) correlated model consisting of the four unidimensional subscales fits the data significantly $\left(\mathrm{H}_{2}\right)$. The inter-factor correlations are significantly different from zero and, as a consequence, a second-order factor model that captures these inter-factor correlations fits the data equally well $\left(\mathrm{H}_{3}\right)$. An implication of this is that AGIS is a single, secondorder composite index $\left(\mathrm{H}_{4}\right)$. The second-order model fits the data very well based on three commonly used indices of fit: root mean square (RMSEA), non-normed fit index (NNFI), and comparative fit index (CFI). The contribution of the concept of ethnic identity (second order) to each of the lower-order constructs is similar. This model is illustrated in Figure 4. 
Figure 4. Second Order Standardized Coefficients. The inter-factor correlations are significantly different from zero and as a consequence a second-order factor model fits the data very well based on three commonly used indices of fit: root mean square (RMSEA), non-normed fit index (NNFI), and comparative fit index CFI). These indices as well as target coefficients showed that the second-order model is a better approximation of Greek American ethnic identity than the first-order model consisting of four constructs.

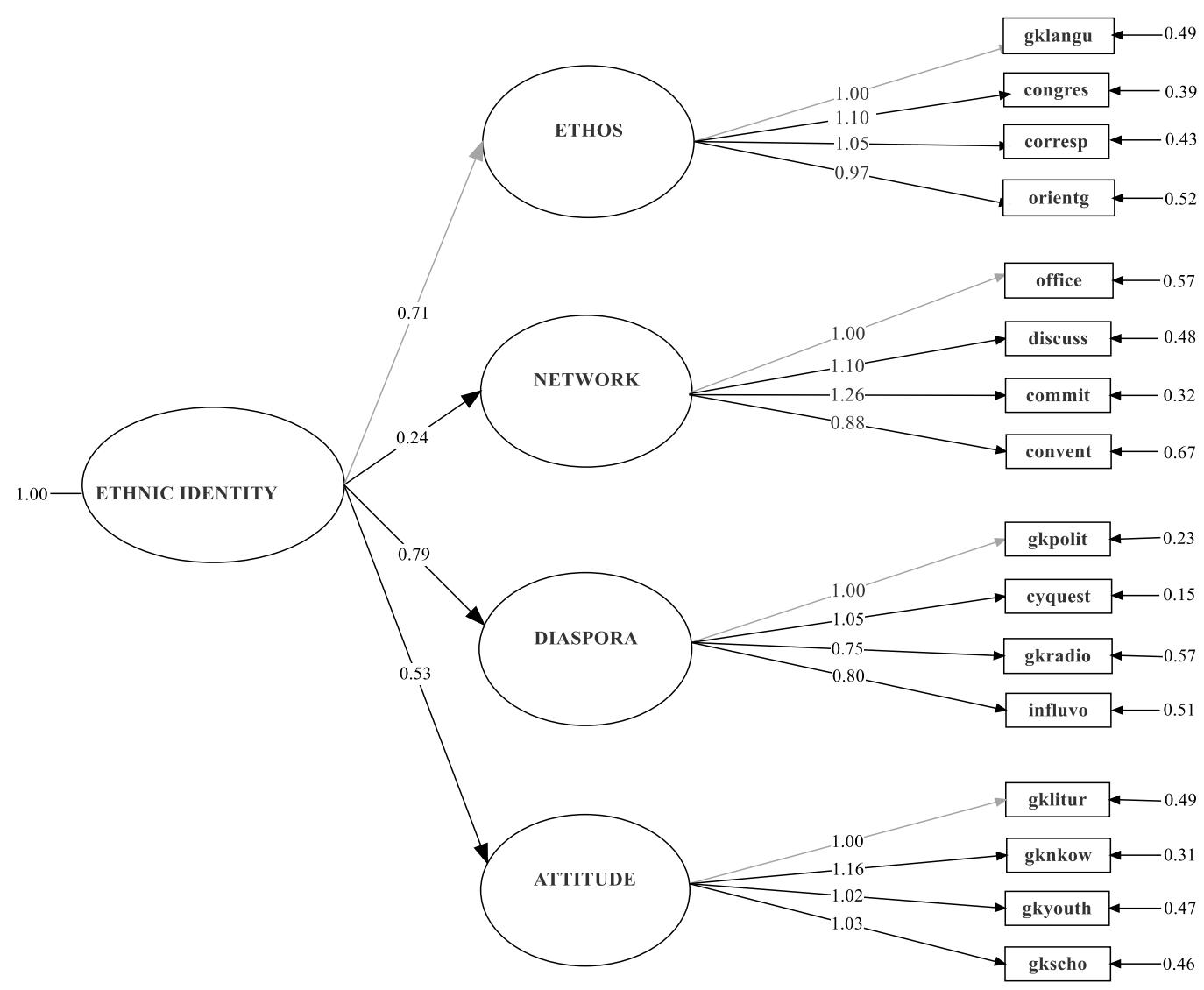

In order to evaluate the fit of the second-order model relative to the first-order model, target coefficients were calculated as developed by Marsh and Hocevar (1985). The target coefficient equals to the ratio of the chi-square of the first-order model to the chi-square of the second-order model and shows the percent of the variation in the first-order factors that can be explained by the second-order construct (Table 10). For example, a target coefficient whose value is 0.973 implies that more than $97 \%$ of the variation in the first-order factors is accounted for by the second-order construct of Greek-American ethnic identity. Overall, the analysis suggests 
that the second-order model is a better approximation of Greek-American ethnic identity than the four-construct first-order model.

The second-order model was significantly replicated with increasingly smaller internal samples $\left(\mathrm{H}_{5}\right): 75 \%, 50 \%, 50 \%$ of the complement, and four-25\% samples; 50\% divided into halves (random sample and complements). Multi-sample analysis of each of these seven samples with the total sample confirms that they are invariant for the lower- and second-order loadings $\left(\mathrm{H}_{6}\right)$. Finally, the veracity of AGIS model is tested by splitting the total sample into two random halves, the calibration and validation sample with coefficients generated in the one-half sample validated in the other one-half $\left(\mathrm{H}_{7}\right)$. Using the single cross validation procedure on 26 pairs of validation and calibration samples of size $n=$ 223, it is demonstrated that fits of the models are statistically equivalent. The significant correlations provide another perspective about the reproducibility of the AGIS scale by smaller internal samples.

Using survey data from northeastern Ohio, the present study makes a contribution to the small body of Greek-American studies, especially regarding ethnic identity. The AGIS has certain limitations that are common to similar scales of measurement of a complex and multifaceted phenomenon like an ethnic identity. In this study, Greek-American ethnic identity is measured indirectly through manifest variables that converge on a four-construct structure. The sample was limited to an area of northeastern Ohio that comprises only six Greek Orthodox parishes out of about five hundred across the United States.

Clearly, there is a need for the replication of this study by surveying from a broader geographic area, such as a regional or a national sample, or a sample from other Greek diasporic communities in other Englishspeaking societies such as Canada, England, and Australia. Additionally, another line of analysis is to use a multisample framework to investigate the role of significant demographic variables such as gender and generation on ethnic identity. This study makes a contribution to the broader literature on ethnic identity by demonstrating the use of structural equation modeling (SEM) to test a theorized model of ethnic identity empirically. The procedures outlined in this study can be used to test the current model with other ethnic groups, in an effort to address the lack of consistency in ethnic identity research (Phinney \& Ong, 2007).

The guidelines presented, herein, map out a best-practice approach to the development and testing of ethnic identity scales, which can facilitate growth in this area of research. While a dependable conceptualization of an ethnic identity scale is needed in order to support a wide variety of research (Phinney \& Ong, 2007), consistency across scale development, and scale testing in the area of ethnic identity is the primary lacunae in ethnic identity research that this investigation achieves to address. 
There is a need for more research in the arena of ethnic identity and the other dynamics of ethnic identity that can be reliably measured. For example, while the current investigation focuses on adults, it would be meaningful to examine the AGIS across different sub-groups within the adult Greek-American community. For example, a resent investigation suggests that young adults approach networking and ethnicity differently than their parents and grandparents (e.g., Fuller-Rowell, Ong, Phinney, 2012; Ikram, et al., 2014; Saint-Blancat \& Zaltron, 2013). Administering the AGIS across a larger sample of participants would provide the ability to see how Greek-Americans, across different age groups, respond regarding their networking behaviors, as well as the role of social media in social networking. Social media is having an impact on networking and as Fuller-Rowell et al. (2012) suggested, may also be a mechanism impacting younger adult's degree of commitment to their ethnic identity.

The research is clear that there is a need for stable consistent measures of ethnic identity. While this model can be applied to other ethnic groups with similar characteristics and minimal modifications, the AGIS has been demonstrated as a strong model of Greek-American ethnic identity. More importantly, the model development provided herein, and the delineated procedures for testing the model, provide the standard for the development of identity scales that can strengthen the research in future studies.

Acknowledgments. The authors want to thank George A. Marcoulides and James P. Allen for their insightful comments and valuable suggestions on an earlier draft of this paper. The authors are also grateful to Joanna Hatzopoulos for her editorial comments as well as the anonymous reviewers whose suggestions greatly improved this manuscript.

\section{References}

Aldrich, H. E., \& Waldinger, R. (1990). Ethnicity and entrepreneurship. Annual Review of Sociology, 16, 111-135.

Anastasiadou, S. D. (2014). A structural equation model describes factors affecting greek students' consumer behavior. Procedia Economics and Finance, 9, 402-406. doi: 10.1016/S2212-5671(14)00041-0

Anderson, D. F., \& Cychosz, C. M.(1994). Development of an exercise identity scale. Perceptual and Motor Skills, 78, 747-751. doi: 10.2466/pms.1994.78.3.747

Anderson, F., Cychosz, C. M., \& Franke, W. D. (2001). Preliminary exercise identity scale (eis) norms for three adult samples. Journal of Sport Behavior, $24,1$. 
Anderson, J. C., \& Gerbing, D.W. (1988). Structural equation modeling in practice. Psychological Bulletin, 103, 411-423. doi: 10.1037/00332909.103.3.411

Arbona, C. R., Jackson, R. H., McCoy, A., \& Blakely, C. (1999). Ethnic identity as a predictor of attitudes of adolescents toward fighting. Journal of Early Adolescence, 19, 323-340.

Barnes-Mauthe, M., Arita, S., Allen, S. D., Gray, S. A., \& Leung, P. (2013). The influence of ethnic diversity on social network structure in a common-pool resource system: Implications for collaborative management. Ecology and Society, 18, 23. Retrieved from http://dx.doi.org/10.5751/ES-05295-180123

Benson, J., \& Bandalos, D. (1992). Second-order confirmatory factor analysis of the reactions to tests scale with cross-validation. Multivariate Behavioral Research, 27, 459-487. doi: 10.1207/s15327906mbr2703_8

Bonett, D. G., \& Wright, T. A. (2000). Sample size requirements for estimating Pearson, Kendall and Spearman correlations. Psychometrika, 65, 23-28. doi: 10.1007/BFo2294183

Boukourakis, A. (2006). It's Greek to me: The politics and shape of GreekAmerican identity. (Master's thesis). Retrieved from / z-wcorg/

Breton, R. (1964). Institutional completeness of ethnic communities and the personal relations of immigrants. American Journal of Sociology, 70, 193205.

Bronfenbrenner, U. (1999). Measuring environment across the life span. In S. L Friedman \& T. D. Wachs (Eds.), Measuring environment across the life span: Emerging methods and concepts (pp. 3-28). Washington, DC: American Psychological Association Press.

Brown, M. W., \& Cudeck, R. (1989). Single sample cross-validation indices for covariance structures. Multivariate Behavioral Research, 24, 445-455. doi: 10.1207/s15327906mbr2404_4

Brown, M. W., \& Cudeck, R. (1993). Alternative ways of assessing model fit. In K. Bollen \& J. Long (Eds.), Testing Structural Equation Models (pp. 136-162). Newbury Park, CA: Sage.

Brown, T. A. (2006). Confirmatory factor analysis for applied research. New York, NY: Guilford Press.

Bryant, F. B., \& Satorra, A. (2012). Principles and practice of scaled difference chi-square testing. Structural Equation Modeling: A Multidisciplinary Journal, 19, 372-398. doi: 10.1080/10705511.2012.687671

Casey, T., \& Dustmann, C. (2010). Immigrant identity, economic outcomes and the transmission of identity across generations. The Economic Journal, 12O, 31-51.

Chacko, E. (2003). Ethiopian ethos and the making of ethnic places in the Washington metropolitan area. Journal of Cultural Geography, 2O, 21-42.

Chen, F., Sousa, K. H., \& West, S. G. (2005). Teacher's corner: Testing measurement invariance of second-order factor models. Structural Equation Modeling: A Multidisciplinary Journal, 12, 471-492. doi: 10.1207/s15328007sem1203_7

Cheung, G. W., \& Rensvold, R. (2002). Evaluating goodness-of-fit indexes for testing measurement invariance. Structural Equation Modeling, 9, 233-255. 
Clogg, R. (1999). The Greek diaspora in the twentieth century. New York, NY: St. Martin's Press.

Constant, A. F., \& Zimmerman, K. F. (2008). Measuring ethnic identity and its impact on economic behavior. Journal of the European Economic Association, 6, 424-433.

Constantinou, S. T. (1982). A geographic-systems approach to ethnicity: The Greek Americans in northeastern Ohio. (Doctoral dissertation). Kent State University, Kent, $\mathrm{OH}$.

Constantinou, S. T. (1989). Dominant themes and intergenerational differences in ethnicity - The Greek Americans. Sociological Focus, 22, 99-118.

Constantinou, S. T., \& Harvey, M. E. (1985). Dimensional structure and intergenerational differences in ethnicity - The Greek Americans. Sociology and Social Research, 69, 234-254.

Constantinou, S. T., \& Harvey, M. E. (2006). The persistence of Greek American ethnicity among age cohorts under changing conditions. In J. W. Frazier, E. Tettey-Fio \& Norah F. Henry (Eds.), Race, ethnicity, and place in a changing America (339-352). Bingingham, NY: Global Academic Publishing.

Constantinou, S. T. (20011). Greek American Ethnicity: Persistence and Change. In J. W. Frazier \& E. Tettey-Fio (Eds.), Race, ethnicity, and place in a changing America, $2^{\text {nd }}$ edition (pp. 57-70). Bingingham, NY: Global Academic Publishing.

Cronbach, L. J., \& Shavelson, R. J. (2004). My current thoughts on coefficient alpha and successor procedures. Educational and Psychological Measurement, 64, 391-418. doi: 10.1177/0013164404266386

Cudeck, R., \& Browne, M. (1983). Cross-validation of covariance structures. Multivariate Behavioral Research, 18, 147-167. doi: 10.1207/s15327906mbr1802_2

Danopoulos, C. (2005). Racial and ethnic attitudes and individual relatedness among Greek-Americans. New Balkan Politics, 9.

Deffa, O. (2016). The impact of homogeneity on intra-group cohesion: A macrolevel comparison of minority communities in a western diaspora. Journal of Multilingual \& Multicultural Development, 37, 343-356.

Epstein, A. L.(2006). Ethos and identity : Three studies in ethnicity. New Brunswick, NJ.

Fan, X., \& Sivo, S. A. (2005). Sensitivity of fit indices to misspecified structural or measurement model components: Rationale of two-index strategy revisited. Structural Equation Modeling: A Multidisciplinary Journal, 12, 343-367. doi: 10.1207/s15328007sem1203_1

Fan, X., \& Sivo, S. A. (2007). Sensitivity of fit indices to model misspecification and model types. Multivariate Behavioral Research, 42, 509-529. doi: 10.1080/00273170701382864

Fan, X., \& Sivo, S. A. (2009). Using $\Delta$ goodness-of-fit indexes in assessing mean structure invariance. Structural Equation Modeling: A Multidisciplinary Journal,16, 54-69. doi: 10.1080/10705510802561311

Farrell, A. M. (2010). Insufficient discriminant validity: A comment on Bove, Pervan, Beatty, and Shiu. Journal of Business Research, 63, 324-327. doi: 10.1016/j.jbusres.2009.05.003 
Flora, D. B., Finkel, E. J., \& Foshee, V. A. (2003). Higher order factor structure of a self-control test: Evidence from confirmatory factor analysis with polychoric correlations. Educational and Psychological Measurement,63, 112-127.

Floyd, F. J., \& Widaman, K. F. (1995). Factor analysis in the development and refinement of clinical assessment instruments. Psychological Assessment, 7, 286-299. doi: 10.1037/1040-3590.7.3.286

Fuller-Rowell, T. E., Ong, A. D., \& Phinney, J. S. (2012). National identity and perceived discrimination predict changes in ethnic identity commitment: Evidence from a longitudinal study of Latino college students. Applied Psychology, 62, 406-426.

George, D., \& Paul, M. (2014). IBM spss statistics 21. Step by step. A simple guide and reference. Boston, MA: Pearson.

Gliem, J. A., \& Gliem, R. R. (2003, October). Calculating, interpreting, and reporting Cronbach's alpha reliability coefficient for likert-type scales. Paper presented at the Midwest Research to Practice Conference in Adult, Continuing and Community Education, Ohio State University, Columbus, Ohio. Retrieved June 19, 2014 from https://scholarworks.iupui.edu/bitstream/handle/1805/344/Gliem+\&+Glie m.pdf?sequence $=1$

Gorsuch, R. L. (1983). Factor analysis. London, England: Lawrence Erlbaum.

Helms, J. E. (1995). An update of Helms's White and people of color racial identity models. In J. G. Ponterotto, J. M. Casas, L. A. Suzuki, \& C. M. Alexander (Eds.), Handbook of Multicultural Counseling (pp. 181-198). Newbury Park, CA: Sage.

Helms, J. E. (1999). Another meta-analysis of the White racial identity attitude scale's Cronbach alphas: Implications for validity. Measurement \& Evaluation in Counseling \& Development (American Counseling Association), 32, 122.

Helms, J. E. (2007). Some better practices for measuring racial and ethnic identity constructs. Journal of Counseling Psychology, 54, 235-246. doi: 10.1037/0022-0167.54.3.235

Huang, C., \& Michael, W. B. (2000). A confirmatory factor analysis of scores on a Chinese version of an academic self-concept scale and its invariance across groups. Educational and Psychological Measurement, 6o, 772-786. doi: 10.1177/0013164400605010

IBM Corp. (2013). IBM spss statistics for windows. Version 22. Armonk, NY: IBM Corp.

Ikran, U. Z., Snijder, M. B., Wit, M. A. S., Schene, A. H., Stronks, K., \& Kunst, A. E. (2016). Preceived ethnic discrimination and depressive symptions: The buffering effects of ethnic identity, religion, and ethnic social network. Sociological Psychiatry and Psychiatric Epidemiology, 51, 679-688.

Issari, P. (2011). Greek American ethnic identity, cultural experience and the 'embodied language' of dance: Implications for counseling. International Journal for the Advancement of Counseling, 33, 252-265. doi: 10.1007/s10447-011-9135-3

Jöreskog, K. G. (2005). Structural equation modeling of ordinal variables using lisrel. $\quad$ Retrieved $3 / 23 / 2012$ from www.ssicentral.com/lisrel/techdocs/ordinal.pdf 
Kaloudis, G. (2008). The influence of the Greek diaspora on Greece and the United States. International Journal on World Peace, 25, 29-60.

Karapanagiotis, F. T. (2008). Greek-American couples: Examining acculturatlion, egalitarianism and intimacy. (Doctoral Dissertation). Drexel University.

Kwan, K. K. (2000). The internal-external ethnic identity measure: Factoranalytic structures based on a sample of Chinese Americans. Educational and Psychological Measurement, 6o, 142-152. doi: 10.1177/0013164400601010

Kwan, K. K., \& Sodowsky, G. R. (1997). Internal and external ethnic identity and their correlates: A study of Chinese American immigrants. Journal of Multicultural Counseling \& Development, 25, 51-67.

Larkin, E. (2006). Diaspora and empire: Toward a new synthesis? Diaspora: $A$ Journal of Transnational Studies, 15, 167-184.

Laroche, M., Kim, C., \& Hui, M. K. (1997). A comparative investigation of dimensional structures of acculturation for Italian Canadians and Greek Canadians. Journal of Social Psychology, 137, 317-331.

Laroche, M., Kim, C., Tomiuk, M. A., Belisle, M. (2005). Similarities in Italian and Greek multi-dimensional ethnic identity: Some implications for food consumption. Canadian Journal of Administrative Sciences-Revue Canadienne Des Sciences De L Administration, 22,143-167.

Marsh, H. W., \& Hocevar, D. (1985). Application of confirmatory factor analysis to the study of self-concept. Psychological Bulletin, 97, 562-582. doi: 10.1037/0033-2909.97.3.562

McLaughlin, A. N., \& Randolph, K. A. (2012). Development of the school support scale for low-income mothers in college. Research on Social Work Practice, 22, 68-76. doi: 10.1177/1049731511415122

Moskos, C. (1999). The Greeks in the United States. In R. Clogg (Ed.), The Greek diaspora in the twentieth century (pp. 103-119). New York, NY: St. Martin's Press.

Moskos, C. C. (1980). Greek Americans, struggle and success. Englewood Cliffs, NJ: Prentice Hall.

Moskos, P., \& Moskos, C. C. (2014). Greek Americans : Struggle and Success. Englewood Cliffs, NJ: Prentice Hall.

Mokrushyna, H. (2013). Is the classic diaspora transnational and hybrid? The case of the Ukrainian Canadian congress. Nations and Nationalism, 19, 799818.

Nicolaidis, M. G. (1989). Aspects of Greek-American ethnic identity: An intergenerational study of Greek-Americans. (Doctoral dissertation). Columbia University Teachers College, New York, NY.

Nunnaly, J. C. (1978). Psychometric theory. New York, NY: McGraw-Hill.

Orozco, V. (2007). Ethnic identity, perceived social support, coping strategies, university environment, cultural congruity, and resilience of Latina/o college students. Ohio State University, Columbus, $\mathrm{OH}$. Retrieved from http://rave.ohiolink.edu/etdc/view?acc\%5Fnum=osu1186609917

Osborne, J. W., \& Fitzpatrick, D. C. (2012). Replication analysis in exploratory factor analysis: What it is and why it makes your analysis better. Practical Assessment, Research \& Evaluation, 17, 1-8. 
Phinney, J. S. (1990). Ethnic-identity in adolescents and adults - Review of research. Psychological Bulletin, 108, 499-514.

Phinney, J. S. (1992). Ethnic-differences in social identity formation in adolescence. International Journal of Psychology, 27, 206-216.

Phinney, J. S. (1996). Understanding ethnic diversity - The role of ethnic identity. American Behavioral Scientist, 4O, 143-152.

Phinney, J. S., \& Chavira, V. (1995). Parental ethnic socialization and adolescent coping with problems related to ethnicity. Journal of Research on Adolescence, 5, 31-53.

Phinney, J. S., Ferguson, D. L., \& Tate, J. D. (1997). Intergroup attitudes among ethnic minority adolescents: A causal model. Child Development, 68, 955969.

Phinney, J. S., \& Ong, A. D. (2007) Conceptualization and measurement of ethnic identity: Current status and future directions. Journal of Counseling Psychology, 54, 271-281.

Ponterotto, J. G., Rao, V. Zweig, J., Rieger, B. P., Schaefer, K., Michelakou, S. Goldstein, H. (2001). The Relationship of acculturation and gender to attitudes toward counseling in Italian and Greek American college students. Cultural Diversity and Ethnic Minority Psychology, 7, 362-375. doi: 10.1037/1099-9809.7.4.362

Raykov, T. (2001). Bias of coefficient for fixed congeneric measures with correlated errors. Applied Psychological Measurement, 25, 69-76. doi: 10.1177/01466216010251005

Raykov, T. (2011). Evaluation of convergent and discriminant validity with multitrait \& ndash; Multimethod correlations. British Journal of Mathematical and Statistical Psychology, 64, 38-52. doi: 10.1348/000711009X478616

Redfield, R., Linton, R., \& Herskovits, M. J. (1936). Memorandum for the study of acculturation. American Anthropologist, 38, 149-152. doi: 10.2307/662563

Rosenthal, D. A., \& Hrynevich, C. (1985). Ethnicity and ethnic identity: A comparative study of Greek, Italian, and Anglo-Australian adolescents. International Journal of Psychology, 20, 723.

Rotheram, M. J., \& Phinney, J. S. (1988). Introduction: Definitions and perspectives in the study of children's ethnic socialization. In J. S. A. R. Phinney (Ed.), Children's ethnic socialization: Pluralism and development (pp. 10-28). Newbury Park, CA: Sage.

Rudmin, F. W. (2003). Critical history of the acculturation psychology of assimilation, separation, integration, and marginalization. Review of General Psychology, 7, 3-37. doi: 10.1037/1089-2680.7.1.3

Saint-Blancat, C. M., \& Zaltron, F. (2013). Making the most of it: How young Romanians and Moroccans in north-eastern Italy use resources from their social media networks. Ethnicities, 13, 795-817.

Schinkel, W. (2013). The imagination of "society" in measurements of immigrant integration. Ethnic and Racial Studies, 36, 1142-1161.

Schumacker, R. E., \& Lomax, R. G. (2010). A beginner's guide to structural equation modeling. New York, NY: Taylor \& Francis Group. Retrieved from http://public.eblib.com/EBLPublic/PublicView.do?ptiID=238908 
Schwartz, S. J., Unger, J., Zamboanga, B. L., \& Szapocznik, J. (2010). Rethinking the concept of acculturation. American Psychologist, 65, 237-251. doi: $10.1037 /$ ao019330

Schwartz, S. J., \& Zamboanga, B. L. (2008). Testing Berry \& \#8217; S model of acculturation. Cultural Diversity and Ethnic Minority Psychology, 14, 275285. doi: 10.1037/aoo12818

Sibley, C. G., \& Houkamau, C. A. (2013). The multi-dimensional model of M \& \#257; Ori identity and cultural engagement. Cultural Diversity and Ethnic Minority Psychology, 19, 97-110. doi: 10.1037/aoo31113

Sodowsky, G. R., Kwan, K., \& Pannu, R. (1995). Ethnic identity of Asians in the United States. In J. G. Ponterotto (Ed.), Handbook of multicultural counseling (pp. 123-154). Thousand Oaks, CA: Sage.

Steenkamp, J. B. E. M., \& Trijp, H. C. M. (1991). The use of lisrel in validating marketing constructs. International Journal of Research in Marketing, 8, 283-299. doi: 10.1016/0167-8116(91)90027-5

Tabachnick, B.G., and Fidell, L.S. (2013). Using multivariate statistics, $6^{\text {th }}$ ed. Boston: Pearson

Tsigilis, N., Koustelios, A., \& Togia, A. (2004). Multivariate relationship and discriminant validity between job satisfaction and burnout. Journal of Managerial Psychology, 19, 666-675. doi: 10.1108/02683940410559365

Ullman, J. B. (2007). Structural Equation Modeling. In B. G. F. L. S. Tabachnick (Ed.), Using multivariate statistics (pp. 653-771). Boston, MA: Pearson/Allyn \& Bacon.

Umana-Taylor, A. J., Diversi, M., \& Fine, M. A. (2002). Ethnic identity and selfesteem among Latino adolescents: Distinctions among the Lation populations. Journal of Adolescent Research, 17, 303-327.

USCB (2016). United States Census Bureau. Retrieved from https://www.census.gov

Valk, A., \& Karu, K. (2001). Ethnic attitudes in relation to ethnic pride and ethnic differentiation. Journal of Social Psychology, 141, 583-601.

Vlachopoulos, S. P., Kaperoni, M., Moustaka, F., \& Anderson, D. F. (2008). Psychometric evaluation of the exercise identity scale among Greek adults and cross-cultural validity. Research Quarterly for Exercise and Sport, 79, 283-299. doi: 10.1080/02701367.2008.10599492

Voutira, E. (2006). Post-Soviet diaspora politics: The case of the Soviet Greeks. [Abstract]. Journal of Modern Greek Studies, 24.

Yanyun, Y., \& Green, S. (2011). Coefficient alpha: A reliability coefficient for the 21st century? Journal of Psychoeducational Assessment, 29, 377-392. doi: 10.1177/0734282911406668 